\title{
Stress Relaxation Behaviour in IN718 Nickel Based Superalloy during Ageing Heat Treatments
}

\author{
Salaheddin Rahimi ${ }^{\mathrm{a}}$, Michael King ${ }^{\mathrm{a}}$, Christian Dumont ${ }^{\mathrm{b}}$ \\ ${ }^{a}$ Advanced Forming Research Centre (AFRC), University of Strathclyde, 85 Inchinnan Drive, \\ Inchinnan, Renfrew, PA4 9LJ. \\ ${ }^{b}$ R\&D Department, Aubert \& Duval (A\&D), F-63770, Les Ancizes, France
}

\begin{abstract}
Designing microstructure of components made from Inconel 718 nickel based superalloy (IN718) with tailored mechanical properties for high temperature applications, require sequential thermo-mechanical processing. This often includes straining and annealing at solution annealing temperature (i.e. $\approx 980^{\circ} \mathrm{C}$ ) followed by water quenching and subsequent aging heat treatments at lower temperatures. In addition to the microstructure development (i.e. precipitation) the aging heat treatment partially relieve the residual stresses generated at previous stages of forging and water quenching, however the stress field will not be completely relaxed.
\end{abstract}

In this study, a series of experiments were conducted on round tensile specimens made from IN718 bar to investigate tensile stress relaxation behaviours at elevated temperatures used for aging heat treatments. The stress relaxation curves obtained can be described by a hyperbolic function with a non-zero asymptotic stress $\left(\sigma_{\infty}\right)$, which seems to be proportional to the initially applied stress $\left(\sigma_{0}\right)$ for a fixed temperature. This behaviour is investigated at temperatures between $620^{\circ} \mathrm{C}$ and $770^{\circ} \mathrm{C}$ that is a temperature range used in industry to perform the aging heat treatments to obtain microstructures with tailored mechanical properties. It has been shown that the $\sigma_{\infty} / \sigma_{0}$ ratio has decreased rapidly with increasing temperature at this range. The relaxation behaviour has been assessed numerically and an empirical relationship has been defined for each temperature that can be used for modelling purposes.

Keywords: Stress Relaxation, IN718, Superalloy, Residual Stress, Mechanical Properties

\section{Introduction}

Due to its excellent creep and fatigue resistance at elevated temperatures and superior durability in exposure to hot gas, nickel based superalloy IN718 is among the selected engineering materials used for manufacturing of critical components for aerospace applications. It is especially suitable for applications at temperatures up to $650^{\circ} \mathrm{C}$ such as combustion chambers and aircraft turbine components (e.g. discs and aerofoils). IN718 is a precipitation hardenable nickel-iron based alloy containing significant fractions of chromium, niobium, molybdenum, and smaller fractions of titanium and aluminium in its chemical composition $[1,2]$. The high temperature mechanical strength of this alloy is owing to the precipitating

${ }^{1}$ Corresponding author:

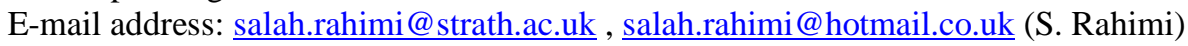

Tel: 0044 (0) 1415345243

Fax: 0044 (0) 1415623387 
phases based on $\mathrm{Ni}_{3} \mathrm{Nb}$ with varying percentages of titanium and aluminium substituting for niobium in the form of $\mathrm{Ni}_{3}(\mathrm{Al}, \mathrm{Ti})[3,4]$.

The most stable $\mathrm{Ni}_{3} \mathrm{Nb}$ precipitate is orthorhombic $\left(\mathrm{D} 0_{\mathrm{a}}\right) \delta$-phase $\left(\approx 700^{\circ} \mathrm{C}-1000^{\circ} \mathrm{C}\right)$ which nucleates at grain boundaries and grows as thin plates laying on the $\{111\}$ planes of the face-centred cubic (fcc) matrix, extending into the grains $[3,5]$. Nucleation of $\delta$-phase can also occur within grains (i.e. intragranularly) in the presence of $\gamma^{\prime \prime}$ that is also based on $\mathrm{Ni}_{3} \mathrm{Nb}$ with different crystallographic structure and stability range [5]. $\gamma^{\prime \prime}$ is the major strengthening phase with body centred tetragonal (bct) crystal structure precipitates between $620^{\circ} \mathrm{C}-900^{\circ} \mathrm{C}$ and dispersed in the fcc $\gamma$ matrix [4]. In addition to $\gamma^{\prime \prime}$, the $\gamma^{\prime}$ with usual cubic ( $\left.\mathrm{Ll}_{2}\right)$ structure and $\mathrm{Ni}_{3}(\mathrm{Al}, \mathrm{Ti})$ chemical stoichiometry, provides additional strengths to IN718 [6]. The $\delta$-phase, due to its morphology, does not have a significant effect on the hardening of the alloy, however, it has specific beneficial effects such as grain boundary pinning to prevent grain growth during solution heat treatments [7], and resistance to grain boundary creep fracture in service [8,9].

Despite being more thermodynamically stable, the kinetics of precipitation of $\delta$-phase below $900{ }^{\circ} \mathrm{C}$ is significantly slower such that it is always preceded by $\gamma^{\prime \prime}$ precipitation. This is however not the case above $900^{\circ} \mathrm{C}$ where the solvus temperature of $\gamma^{\prime \prime}$ precipitation is reached [1]. Since both phases are based on niobium and only a limited amount of niobium exist in the chemical content, the nucleation and growth of the $\delta$-phase indicates the loss of $\gamma^{\prime \prime}$ phase. $\gamma^{\prime \prime}$ phase is thermodynamically metastable and long term exposure to temperatures over $650{ }^{\circ} \mathrm{C}$ leads to its transformation to the most thermodynamically stable form of $\mathrm{Ni}_{3} \mathrm{Nb}$ or the $\delta$-phase [4]. Long exposure times in excess of 3000 hours has been seen to result in decomposition of $\gamma^{\prime \prime}$ in to $\gamma^{\prime}\left(650^{\circ} \mathrm{C}-850^{\circ} \mathrm{C}\right)$ or $\delta\left(750^{\circ} \mathrm{C}-1000^{\circ} \mathrm{C}\right)$ phases [3]. The volume fractions of $\gamma^{\prime \prime}$ and $\gamma^{\prime}$ in IN718 that is subjected to a full heat treatment cycle including solution annealing and double aging heat treatment approaches $20 \%$ and $5 \%$, respectively $[10,11]$. The theoretical maximum of $\gamma^{\prime \prime}$ in IN718 is $21 \%$.

Control of the microstructure during manufacturing processes of components (e.g. turbine discs) made from IN718 is essential to the development of the mechanical properties required for high temperature applications. These parts typically undergo two stages of thermo-mechanical processing including (i) solution heat treatment at temperatures around the $\delta$-phase solvus temperature that can be slightly above or below this temperature followed by rapid cooling (i.e. water quenching), and (ii) subsequent heat treatments at lower temperatures (i.e. $720^{\circ} \mathrm{C}$ and $620{ }^{\circ} \mathrm{C}$ ). The benefits of heat treatments at $720^{\circ} \mathrm{C}$ and $620{ }^{\circ} \mathrm{C}$ are firstly to partially relieve the residual stresses induced by water quenching following the solution treatment process, and secondly to precipitate $\gamma^{\prime \prime}$ and $\gamma^{\prime}$ intragranularly which are critical for high temperature creep resistance.

If the material undergoes a solution heat treatment below the $\delta$-phase solvus temperature (i.e. sub-solvus), a large quantity of $\delta$-phase resides at the grain boundaries thus preventing substantial grain coarsening through grain boundary pinning. This sub-solvus solution heat treatment however, reduces the potential volume fraction of intragranular $\gamma^{\prime \prime}$ and hence there is less contribution to the material's mechanical properties due to the fact that both $\delta$-phase and $\gamma^{\prime \prime}$ are based on $\mathrm{Ni}_{3} \mathrm{Nb}$. On the other hand, a solution heat treatment above the $\delta$-phase solvus temperature (i.e. super-solvus) results in a microstructure with maximised intragranular precipitation of $\gamma^{\prime \prime}$ and minimised $\delta$-phase at the grain boundaries which makes the material prone to high temperature grain boundary creep fracture and increased notch sensitivity $[8,9]$. The post solution heat treatment water quenching process results in a higher density of nucleation sites for $\gamma^{\prime \prime}$ precipitation, and the volume fraction of the $\gamma^{\prime \prime}$ precipitates increases substantially on aging between 
$575^{\circ} \mathrm{C}$ and $720^{\circ} \mathrm{C}$ for up to 100 hours [3]. This in turn leads to the generation of high amounts of interfacial areas between the $\gamma^{\prime \prime}$ and the $\gamma$ matrix which makes the material metastable by increasing the overall energy level of the entire system. A prolonged aging heat treatment at temperatures closer to the lower limit of the $575^{\circ} \mathrm{C}-720^{\circ} \mathrm{C}$ range results in increased $\gamma^{\prime \prime}$ precipitation without excessive particle growth, whereas aging at temperatures towards the upper limit of this range causes reduction of the interfacial area between $\gamma^{\prime \prime}$ and the $\gamma$ matrix by an increase in the size of $\gamma^{\prime \prime}$ precipitating phase, known as Ostwald ripening, leading to degraded mechanical properties [3]. The optimised occurrence of second phase precipitations in IN718 requires the availability of appropriate amounts of alloying elements in the matrix. This means that if the alloying elements precipitate in the form of unwanted phases, such as carbides, then the $\delta, \gamma^{\prime}$ and $\gamma^{\prime \prime}$ phases will not precipitate correctly, with a consequence that the material doesn't obtain its full strength.

The thermal gradients seen during water quenching from the solution heat treatment temperature can be severe enough to generate residual stress fields of significantly high magnitudes [12-16]. The subsequent aging heat treatments at lower temperatures (i.e. $575^{\circ} \mathrm{C}-720^{\circ} \mathrm{C}$ ) employed for microstructure modifications might also relieve these stresses through creep deformation, however it is rare for the stress field to be completely relaxed. These stresses can be beneficial or detrimental to the fatigue performance of the material in service $[17,18]$, but most importantly, they can influence the strategies based on which the final machining operations of the manufacturing processes are executed. This is primarily due to the redistribution of residual stresses caused by material removal which results in the movement of the remaining material out of specified dimensional tolerances. Hence why, understanding the generation of residual stresses during quenching and their evolution throughout the aging heat treatment becomes imperative.

The stress relaxation test allows some of the material's high temperature characteristic behaviours such as the stress sensitivity exponent and the average internal stress, to be determined phenomenologically, in a relatively short period of time [19]. These characteristic properties can be used in relationships describing the active physical mechanisms during high temperature deformation. The aim of this study is to empirically predict the stress relaxation behaviour of highly loaded IN718 nickel based superalloy with the application of hot relaxation tests at the usual temperature range (i.e. $575^{\circ} \mathrm{C}-720^{\circ} \mathrm{C}$ ) practiced in industry for aging heat treatments. The modelling of stress relaxation at the microstructural scale is beyond the scope of this investigation as it requires information on more than one microstructure parameter (e.g. dislocation density) which underlies the highest thermal and complex mechanical loads. A physically based model to simulate stress relaxation based on microstructure constituents can be found elsewhere [20].

\section{Experimental Procedure}

\subsection{Material}

The material chosen for this study is IN718 superalloy in the form of $20 \mathrm{~mm}$ diameter and $1000 \mathrm{~mm}$ long bars. The nominal chemical composition for this material, supplied by the manufacturer, is provided in Table 1 . The as-received bars were heat treated at $980^{\circ} \mathrm{C}$ for one hour followed by water quenching, and then a sufficient number of round tensile specimens with threaded ends were made from the heat treated material according to the ASTM standard [21]. Samples were also manufactured from the as-received material for comparison between the tensile properties before and after the 1 hour heat treatment at $980^{\circ} \mathrm{C}$.

The microstructures of the as received and heat treated materials were characterised using electron backscatter diffraction (EBSD). For the EBSD analyses, samples were cut from the as received and heat 
treated materials along and perpendicular to the length of the bars, and mechanically ground and polished to a mirror finished condition. The samples were then subjected to a final stage of vibratory polishing for a period of 3 hours using diluted colloidal silica (i.e. 70\% deionised water) suspension. The acquisition of EBSD maps were carried out using a fully automated HKL-EBSD system interfaced to a FEI Quanta-250 field-emission gun scanning electron microscope (SEM), with an accelerating voltage of $20 \mathrm{kV}$ and a 100 $\mu \mathrm{m}$ dia. aperture. The acquisition time was set to $40 \mathrm{~ms}$, collecting at least 1 frame for each point. At least 4 maps have been collected per sample, and in all cases, a minimum of $93 \%$ of the scanned areas with a typical size of $500 \mu \mathrm{m} \times 500 \mu \mathrm{m}$, were indexed.

Table 1: Chemical composition of the IN718 material investigated in this study (wt\%)

\begin{tabular}{|c|c|c|c|c|c|c|c|c|}
\hline Elements & $\mathbf{N i}$ & $\mathbf{C r}$ & $\mathbf{F e}$ & $\mathbf{M o}$ & $\mathbf{N b}$ & $\mathbf{A l}$ & $\mathbf{C}$ & $\mathbf{T i}$ \\
\hline$(\mathbf{w t} \%)$ & Base & 18.00 & 18.50 & 3.00 & 5.20 & 0.50 & 0.04 & 0.90 \\
\hline
\end{tabular}

\subsection{Tensile Experiments}

The tensile specimens were designed according to the ASTM standard for testing of metallic materials in tension [21]. A schematic representation of the round tensile sample with all the relevant dimensions are shown in Figure 1. The tests were conducted on the material in the as received and heat treated conditions at room temperature (RT). Tests were also conducted on samples in the heat treated condition (i.e. annealed at $980^{\circ} \mathrm{C}$ for one hour) at $620^{\circ} \mathrm{C}, 670^{\circ} \mathrm{C}, 720^{\circ} \mathrm{C}$ and $770^{\circ} \mathrm{C}$ that were the temperatures chosen for the stress relaxation experiments described in the following section. The tension experiments were carried out using a standard tensile test machine (Zwick/Roell-Z150) at a crosshead displacement of $2 \mathrm{~mm} / \mathrm{minute}$ equivalent to a strain rate of $10^{-3} 1 / \mathrm{s}$, and a ceramic extensometer with a $20 \mathrm{~mm}$ gauge length was implemented to measure strain.

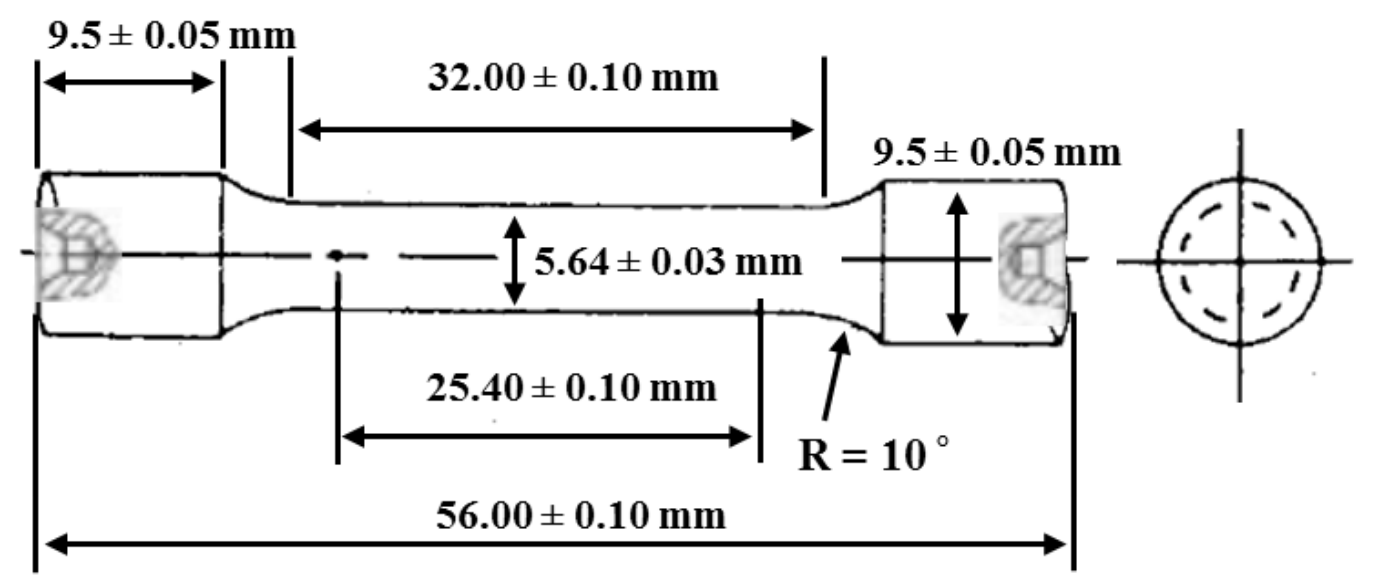

Figure 1: Schematic sketch of the standard tensile test sample used for the manufacture of specimens, with the dimensions provided.

\subsection{Stress Relaxation Methodology and Tests}

The stress relaxation experiments were conducted based on the ASTM [19] standard using a screw-drive Zwick/Roell-Z150 testing machine with an adapted furnace capable of reaching a steady state target temperature after about 20 minutes. Based on this practice, the specimens were first deformed under 
constant crosshead speed of $1 \mathrm{~mm} / \mathrm{min}$ which produces an average strain rate of $\dot{\varepsilon}=4.8 \times 10^{-4} 1 / \mathrm{s}$, until an initial plastic strain of $\varepsilon_{\mathrm{op}}$ or an initial stress of $\sigma_{0}$ is reached. Then the crosshead motion of the tensile test machine was abruptly stopped; subsequently, the stress is recorded as a function of time during the relaxation phase, while the strain is kept constant. This has been schematically illustrated in Figure 2.

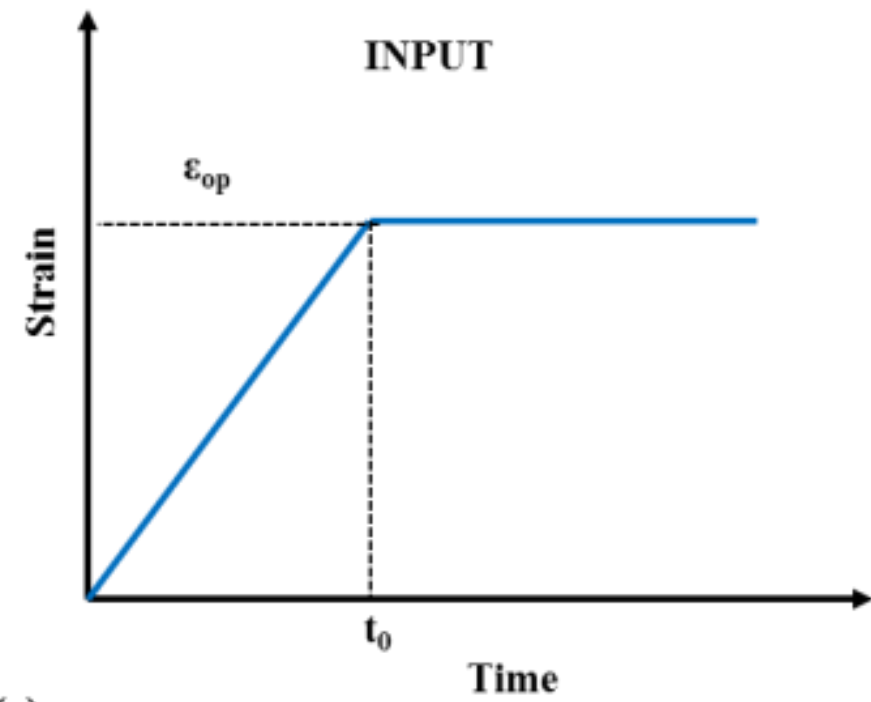

(a)

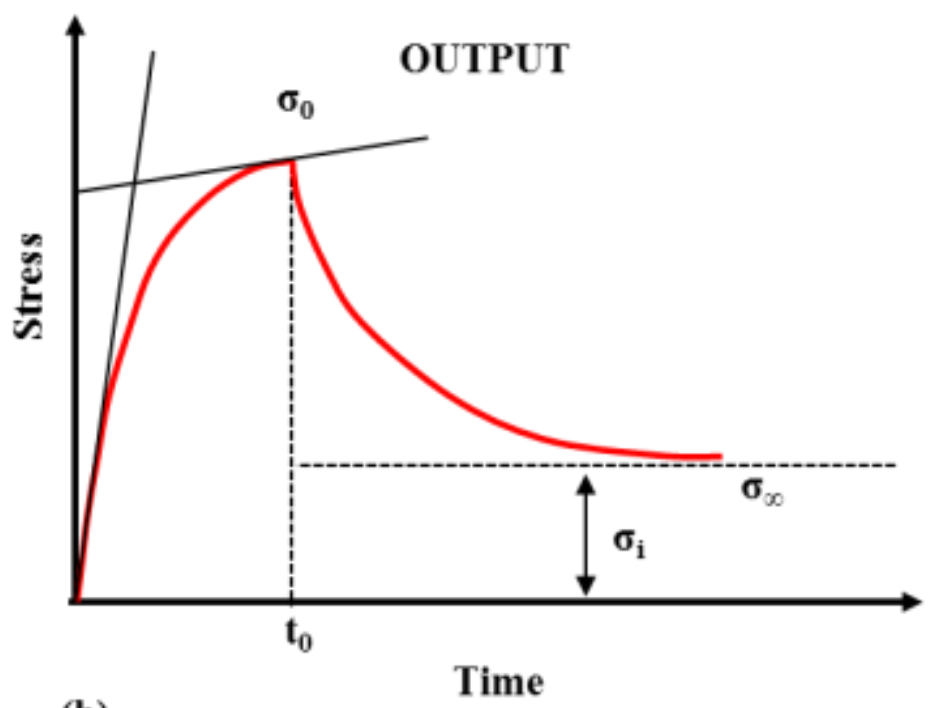

(b)

Figure 2: Schematic representations of (a) constant strain rate deformation (Input), and (b) stress relaxation (Output) as functions of time.

The stop point of the crosshead motion corresponds to a total constant strain $\left(\varepsilon_{t o t}\right)$ which includes the different contributions of plastic strain $\left(\varepsilon_{p l}\right)$ and elastic strain $(\varepsilon e l)$. The contribution of elastic strain can be represented by the measured stress $(\sigma)$ and Young's modulus $(E)$ of the material (Equation 1$)$.

$$
\varepsilon_{t o t}=\varepsilon_{p l}+\varepsilon_{e l}=\varepsilon_{p l}+\frac{\sigma}{E}
$$

Equation 1

During the constant crosshead motion (i.e. loading in tension), not only does the specimen undergo elastic deformation but the entire tensile testing rig is also elastically loaded according to Hooke's law, depending on the magnitude of the applied load. Hence the stress relaxation experiment needs to be conducted on a hard testing rig with very high stiffness. The interaction between the specimen and the testing rig can be visualised by the aid of a mechanical model. In this model the elastic deformations are represented by springs and the time dependent plastic deformations by dashpots [22]. Figure 3 schematically shows the material behaviour by a combination of springs and a dashpot. The deformation of the dashpot is not straight forward and can only be described by a constitutive relation between stress $(\sigma)$, strain $\left(\varepsilon_{p}\right)$, strain rate $\left(\dot{\varepsilon}_{\mathrm{p}}\right)$ and temperature $(T)$ (Equation 2). The exact form of Equation 2 depends on the kinetics associated with the mechanisms that are controlling the plastic flow.

$$
F\left(\sigma, \varepsilon_{p}, \dot{\varepsilon}_{p}, T\right)=0
$$




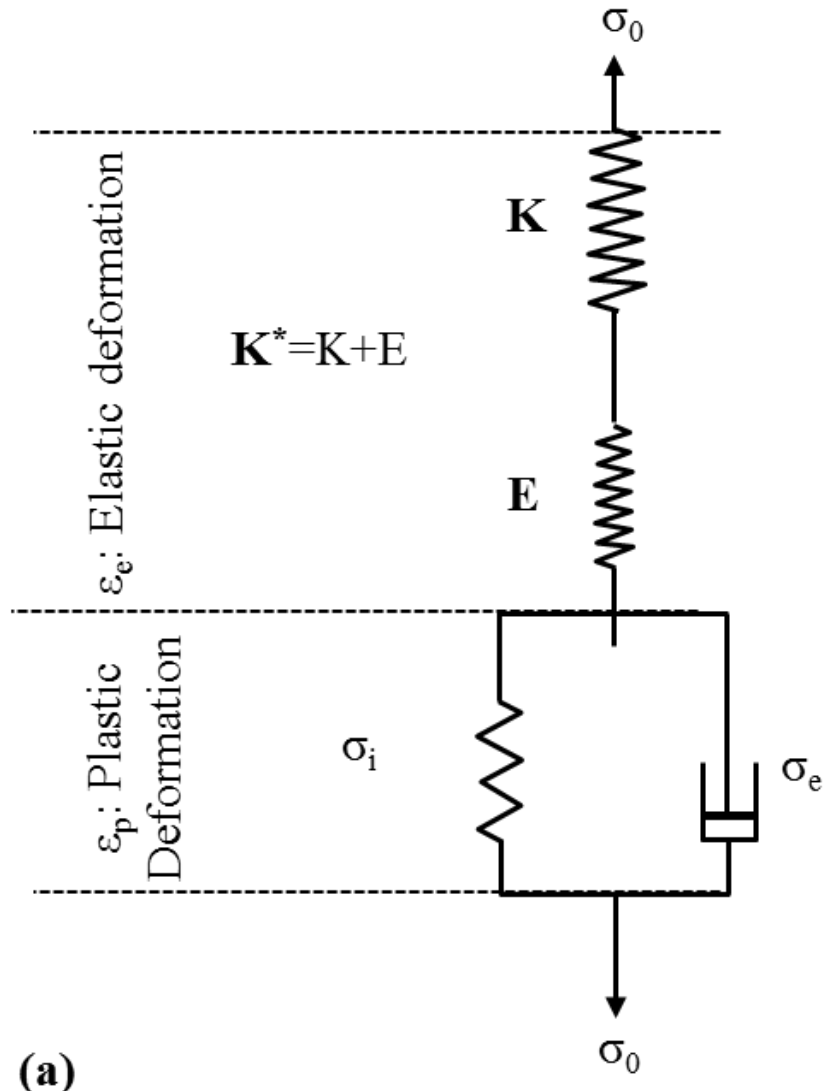

(a)

Figure 3: (a) The mechanical model used to represent the elastic and plastic deformation in stress relaxation tests; $\sigma_{e}, \sigma_{i}$, and $\sigma_{0}$ are effective stress, internal stress and applied stress, respectively, (b) a photograph showing the tensile test rig taken just after the termination of a test at $720^{\circ} \mathrm{C}$.

In stress relaxation test, from the beginning of the test where the strain is zero $(\varepsilon=0)$ up to a point when the crosshead motion is stopped $\left(\varepsilon=\varepsilon_{o p}\right)$, the crosshead velocity of the testing machine $(v)$ is matched by the elastic $\left(\dot{L}_{E}\right)$ and plastic $\left(\dot{L}_{P}\right)$ deformation rates of the specimen and the elastic extension rate of the machine $\left(\dot{L}_{M}\right)$ (Equation 3).

$$
v=\dot{L}_{E}+\dot{L}_{P}+\dot{L}_{M}
$$

Equation 3

Upon the termination of the crosshead motion the velocity term in Equation 3 (i.e. the crosshead velocity) becomes zero $(v=0)$. If the stiffness of the machine is described as $K$ and the applied force as $P$, then the machine stiffness can be defined as $K=d p / d L_{M}$. Substituting these terms in Equation 3 would lead to Equation 4.

$$
\dot{L}_{E}+\dot{L}_{P}+\frac{\dot{P}}{K}=0
$$

Equation 4

In Equation 4 the force is described as a force rate $(d P / d t)$. Dividing all terms by the initial length of the specimen $\left(L_{0}\right)$ and defining the stress rate as $\dot{\sigma}=\dot{P} / A_{0}$, in which $A_{0}$ is the initial cross section of the 
specimen, will provide Equation 5 in which the apparent stiffness of the system is defined as a function of the machine stiffness and Young's modulus of the specimen.

$$
\frac{1}{K^{*}}=\frac{\Delta l_{t}}{P}=\frac{1}{K}+\frac{l}{E \cdot A_{0}}
$$

Equation 5

In Equation $5, K^{*}$ is the universal stiffness that is inversely proportional to the total elastic elongation $\left(\Delta l_{t}\right)$ acquired under a given load $(P), K$ is the machine's stiffness, $E$ is the modulus of elasticity of the material and $l$ and $A o$ respectively are the initial length and cross section of the specimen. Note that the total elastic elongation $\left(\Delta l_{t}\right)$ is the measured crosshead displacement. The only complication with Equation 5 is that the Young's modulus $(E)$ of the material under investigation should be known at the testing temperature. Therefore, the Young's modulus at each testing temperature was measured using a high temperature Maytech extensometer with a $20 \mathrm{~mm}$ initial gauge length. For the stress relaxation tests, the extensometer has then been removed upon reaching the target initial plastic strain $\left(\varepsilon_{o p}\right)$. This has firstly been due to difficulty with the temperature control of the furnace having a slot opened for the installation of the extensometer, and secondly because the extensometer's legs tend to slide after remaining at high temperature for relatively long periods of time which adds uncertainty to the measurement. Following the introduction of the initial plastic strain $\left(\varepsilon_{o p}\right)$, the samples were allowed to relax for 40-60 minutes depending on the load decrease rate. After this time all the recorded loads vs. time curves tended toward a non-zero value corresponding to an asymptotic stress denoted as $\sigma_{\infty}$ (see Figure $2 \mathrm{~b}$ ). This is measured after a relaxation period by applying an incremental unloading technique that is widely used in previous studies [23-29].

Based on the incremental unloading principles, the plastic strain rate at zero equivalent stress $\left(\sigma_{e}=0\right)$ is equal to zero. Therefore at stresses below the internal stress level, the relaxation is negative which then results in an increase in the stress vs. time curve upon the applied unloading. The internal stress can be considered as the applied stress at zero strain rate. The determination of absolute zero strain rate is practically impossible due to the relaxation happening in the machine [28]. Hence a range of stress can be determined within which the strain rate is close to zero. The width of this stress range depends on the sensitivity of the equipment and also properties of the material under investigation [26]. Different materials may have a smaller or broader stress range within which the plastic strain rate is less than the sensitivity of the equipment. Figure 4 schematically shows the incremental unloading processes for characterisation of internal stress $\left(\sigma_{i}\right)$. Table 2 summarises the test matrix including the percentages of deformations and the test temperature for stress relaxation tests carried out during the course of this study. 


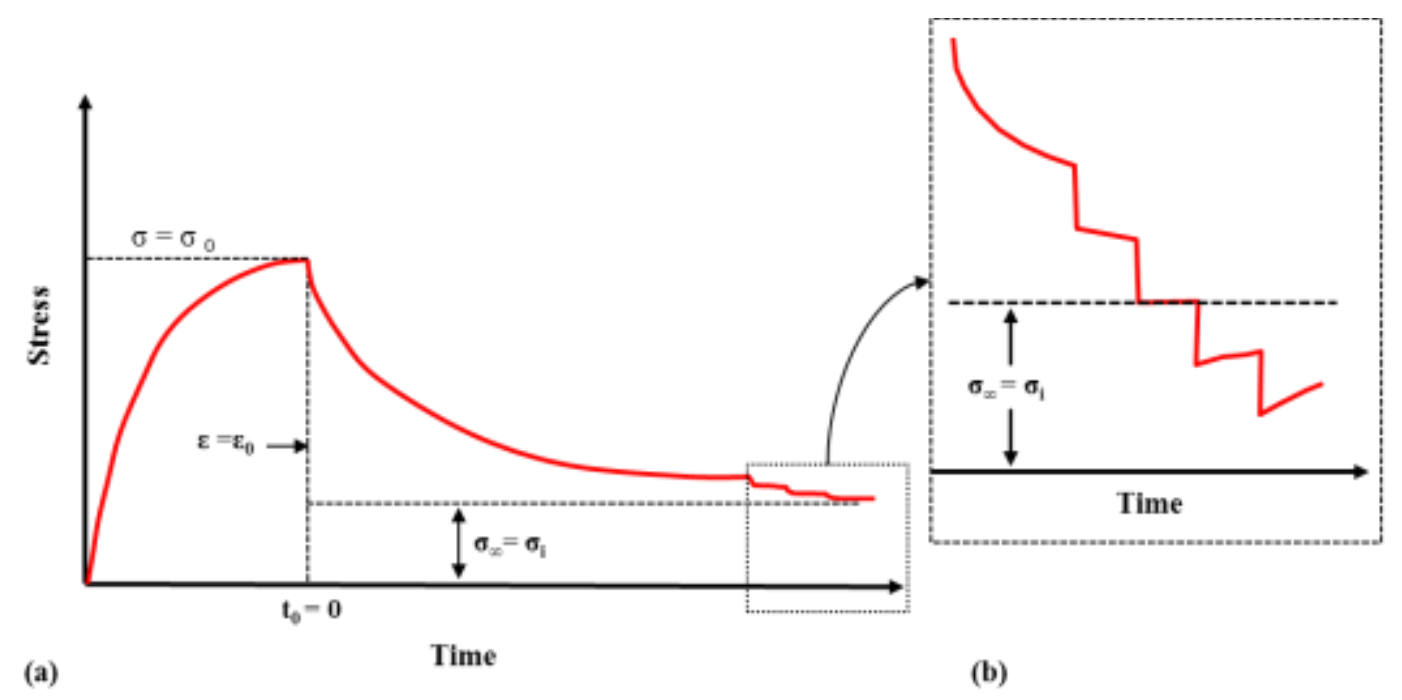

Figure 4: (a) Schematic illustration of a typical stress relaxation curve including three stages of initial loading to $\sigma=\sigma_{0}$, relaxation and incremental unloading, (b) The magnified incremental unloading stage highlighted in (a) for the determination of internal stress $\left(\sigma_{i}=\sigma_{\infty}\right)[29]$.

Table 2: Summary of stress relaxation experiments at different temperatures and applied strain

\begin{tabular}{|c|c|c|}
\hline Material's Condition & Temperature $\left({ }^{\circ} \mathrm{C}\right)$ & \multirow{2}{*}{ Strain $(\%)$} \\
\hline \multirow{3}{*}{$\begin{array}{c}\text { Heat Treated for } \\
1 \mathrm{hr} \text { at } 980^{\circ} \mathrm{C}\end{array}$} & 620 & \multirow{2}{*}{$0.5,1,2$} \\
\cline { 2 - 2 } & 720 & \\
\cline { 2 - 2 } & 770 & \\
\cline { 2 - 3 } & \multicolumn{2}{|c|}{0} \\
\hline
\end{tabular}

\section{Results}

\subsection{Materials Microstructure}

Figure 5a and $\mathrm{b}$ show SEM appearances of the as received and heat treated (i.e. 1 hour at $980^{\circ} \mathrm{C}$ ) microstructures containing $\delta$-phase (i.e. white segments) at grain boundaries. The as received microstructure consisted of polygonal grains with an average grain size of $3.0 \pm 0.2 \mu \mathrm{m}$ perpendicular to the length, and $3.8 \pm 0.2 \mu \mathrm{m}$ along the length of the as received bar. The one hour heat treatment at $980^{\circ} \mathrm{C}$ has resulted in the dissolution of $\delta$-phase by approximately 3-5\% volume fraction (Figure 5a, b) and a slight grain growth of about $1 \mu \mathrm{m}$, such that the average grain size of the heat treated microstructure was measured to be $3.9 \pm 0.3 \mu \mathrm{m}$ perpendicular to the length and $4.6 \pm 0.3 \mu \mathrm{m}$ along the length of the bar. Figure $5 c$ and $d$ show orientation image maps (OIM) of the as received and the heat treated materials using inverse pole figure (IPF) colouring with respect to the normal to the plane of view. Both microstructures have random texture and no preferred orientation. Other than a slight difference in the grain size, no measurable difference is observed in microstructures (i.e. texture and grain boundary misorientation) along and perpendicular to the length of the bars for both the as received and heat treated materials. 


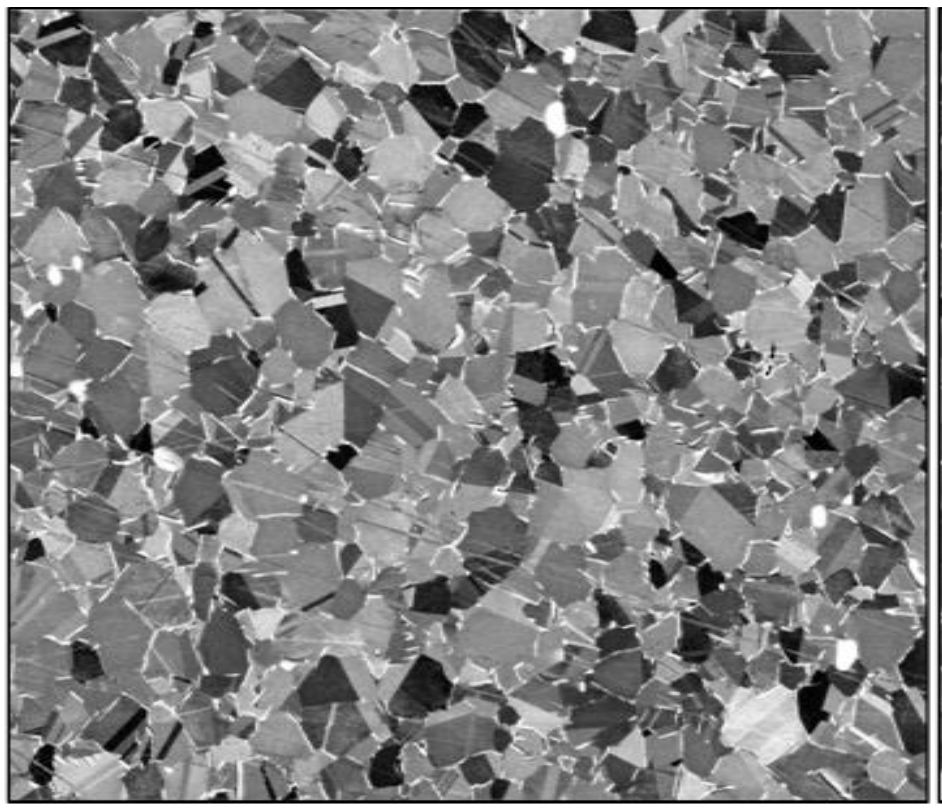

(a)

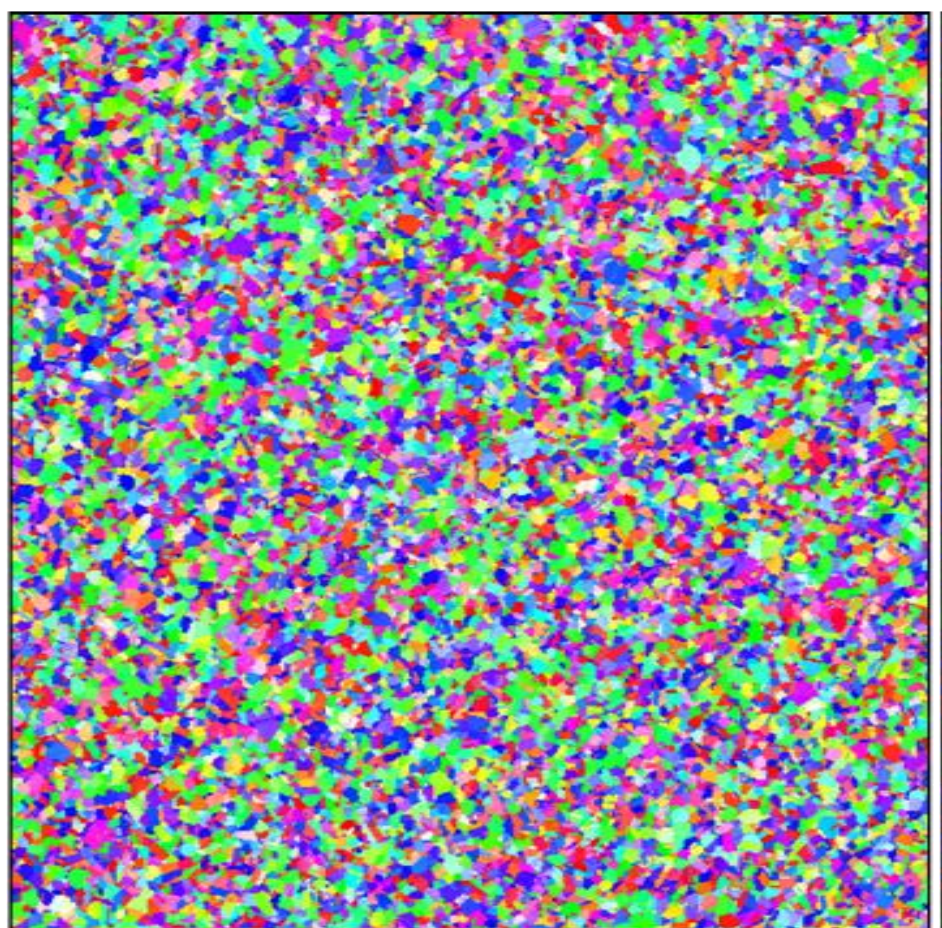

(c)

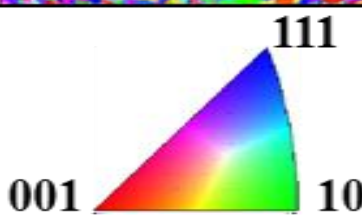

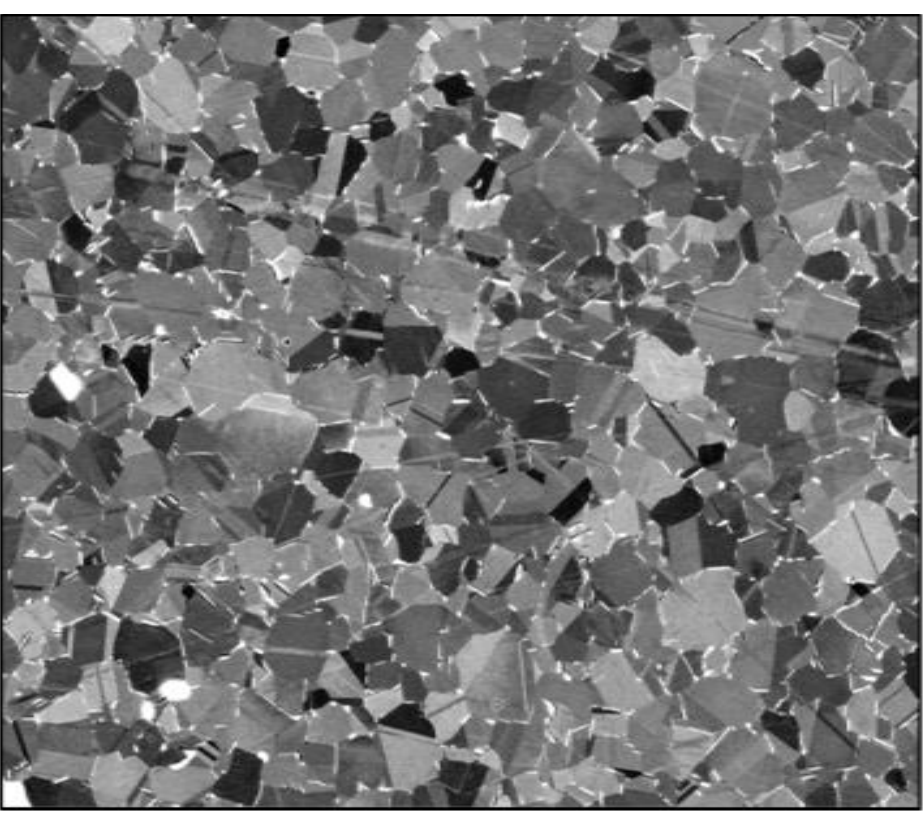

(b)

$40 \mu \mathrm{m}$

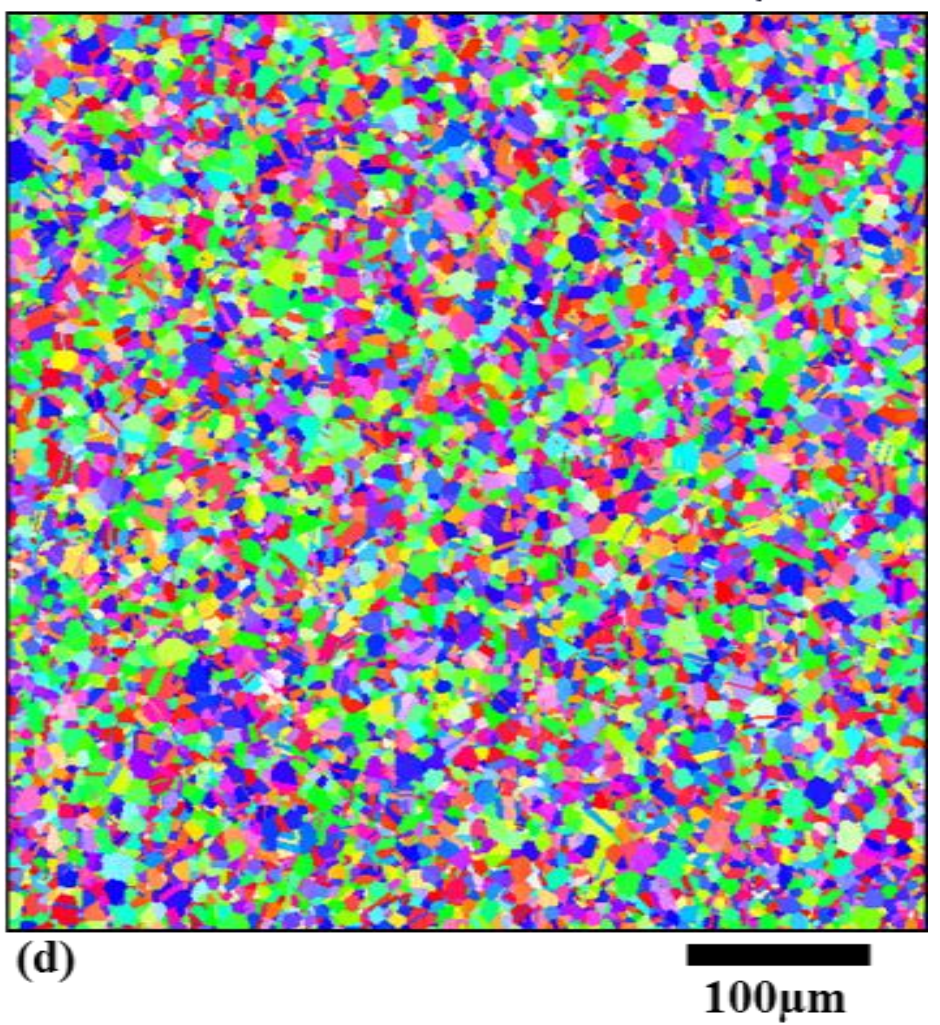

Figure 5: SEM micrographs of (a) the as received material, and (b) after 1 hour heat treatment at $980^{\circ} \mathrm{C},(\mathrm{c})$ and (d), respectively, are the EBSD IPF colouring maps with respect to the normal to the plane of view of the as received and heat treated materials. $\delta$-phase in (a) and (b) appears as white particles lying predominantly on the grain boundaries. Note that the few large white features are not part of the microstructure and can be colloidal silica left from the polishing stage of the sample preparation.

The aging heat treatments of the solution treated $\left(1 \mathrm{hr}\right.$ at $\left.980{ }^{\circ} \mathrm{C}\right)$ microstructure at the temperature range used for the stress relaxation tests (i.e. $620^{\circ} \mathrm{C}-770{ }^{\circ} \mathrm{C}$ ) had no measurable influence on the size and 
distribution of $\delta$-phase by SEM, and the grain size distribution. Figure 6 shows the plot of average grain size for the as received material and the heat treated materials including the solution annealed $\left(1 \mathrm{hr}\right.$ at $\left.980^{\circ} \mathrm{C}\right)$ microstructure plus those aged at $720^{\circ} \mathrm{C}$ and $770^{\circ} \mathrm{C}$ for $\approx 1$ hour following the solution annealing. It can be seen that only solution annealing causes $\approx 1 \mu \mathrm{m}$ increase in the average grain size compared to that of the as received microstructure, and further aging heat treatment has no influence on the grain size.

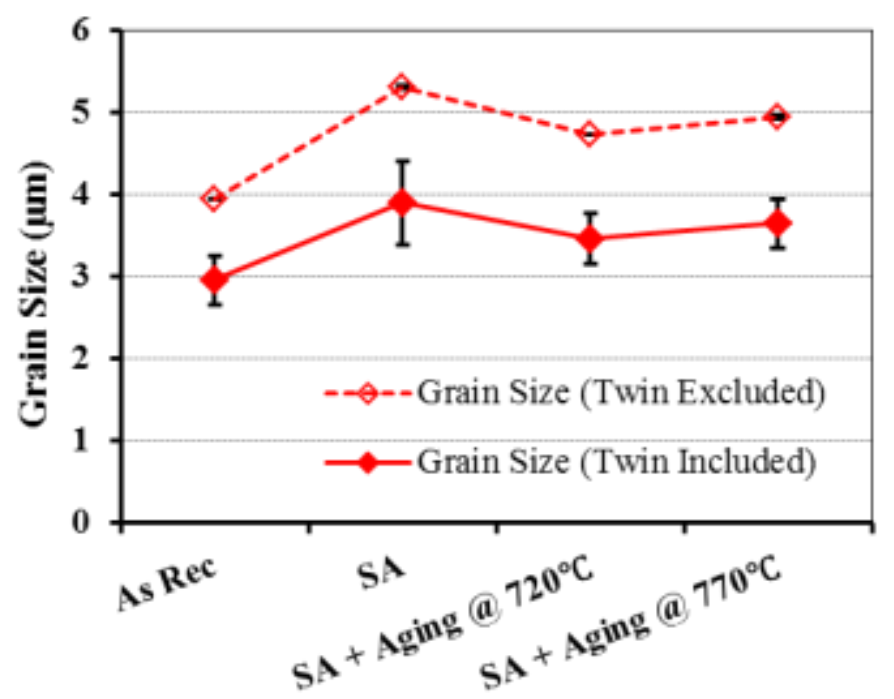

Figure 6: Plot of average grain size as a function of solution annealing $(\mathrm{SA})$ heat treatment $\left(1 \mathrm{hr}\right.$ at $\left.980^{\circ} \mathrm{C}\right)$ and subsequent aging heat treatments at $720^{\circ} \mathrm{C}$ and $770^{\circ} \mathrm{C}$. For each microstructure, the grain size has been evaluated by including and excluding twins with $\sum 3$ misorientation as grain boundaries, individually. Data for the as received (As Rec) material is provided for the aid of comparison. The error bars are the second root of sum of the squares of standard deviations calculated for at least four EBSD maps per microstructure.

\subsection{Tensile Properties}

Figure 7 shows the full engineering stress-strain curves obtained for the solution treated material tested at room temperature and at elevated temperatures ranging from $620^{\circ} \mathrm{C}$ to $770^{\circ} \mathrm{C}$. The data for the as received material is also provided for the aid of comparison. The measured tensile properties for these conditions, including Young's modulus $(E)$, yield stress [Rp0.2\%], ultimate tensile strength (UTS) and maximum elongation are summarised in Table 3. For the solution treated material, Young's modulus is decreased from $195 \mathrm{GPa}$ at room temperature to $143 \mathrm{GPa}$ at $770^{\circ} \mathrm{C}$ (Figure 7 and Table 3). Increasing temperature from $\mathrm{RT}$ to $620^{\circ} \mathrm{C}$ has resulted in $\approx 50 \mathrm{MPa}$ reduction in the yield strength, while increasing temperature from $620^{\circ} \mathrm{C}$ to $720^{\circ} \mathrm{C}$ led to a significant increase ( $>200 \mathrm{MPa}$ ) in the yield strength followed by a slight decrease $(\approx 30 \mathrm{MPa})$ when further increasing temperature from $720^{\circ} \mathrm{C}$ to $770^{\circ} \mathrm{C}$ (see Figure 7 and Table 3). Similarly to the yield stress trend, the UTS has decreased from $965 \mathrm{MPa}$ at RT to $778 \mathrm{MPa}$ at $620^{\circ} \mathrm{C}$, and then increased to $819 \mathrm{MPa}$ when increasing temperature from $620^{\circ} \mathrm{C}$ to $670^{\circ} \mathrm{C}$. Increasing temperature beyond $670^{\circ} \mathrm{C}$ to $770^{\circ} \mathrm{C}$ has resulted in significant decrease in the UTS. The percentage of elongation of the as received and solution treated materials at room temperature are measured to be $39 \%$ and $42 \%$, respectively. The percentage of elongation for the heat treated microstructure is increased to $48 \%$ by increasing the temperature from RT to $620^{\circ} \mathrm{C}$. This has then slightly reduced for the tests at $670^{\circ} \mathrm{C}$ and $720^{\circ} \mathrm{C}$, however, that of the test carried out at $770^{\circ} \mathrm{C}$ has reduced significantly to $25 \%$ (see Figure 7 and Table 3). 


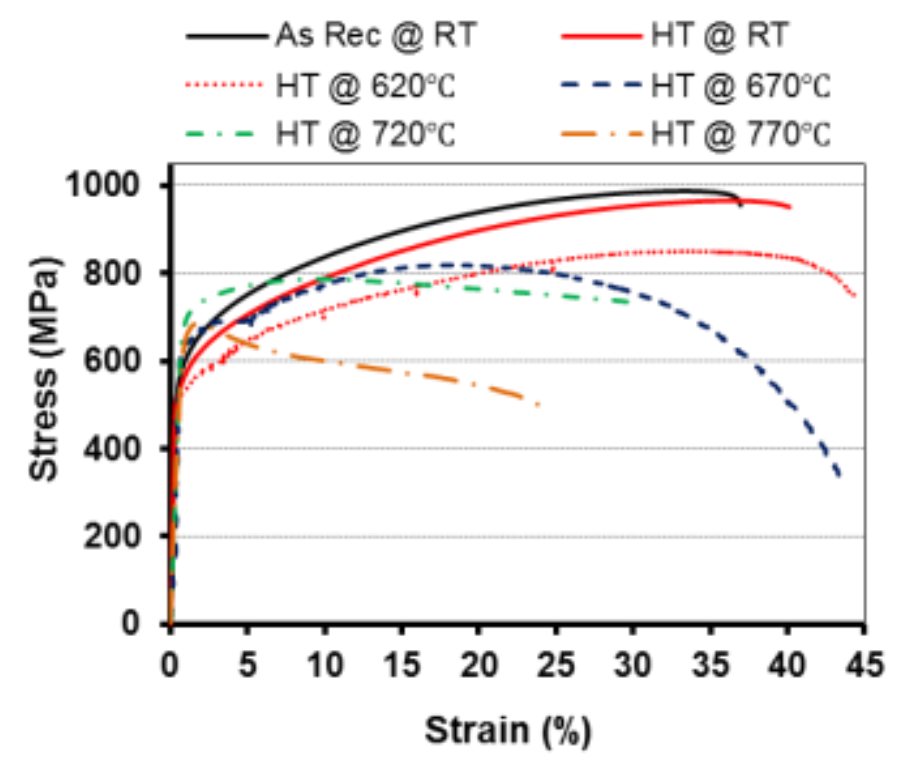

Figure 7: Full engineering stress-strain curves for the heat treated microstructure (HT) at different temperatures. Data for the as-received material is provided for the aid of comparison.

Table 3: The measured mechanical properties of the IN718 material in the as-received and solution treated condition at room temperature and elevated temperatures. The errors are the standard error of several trials.

\begin{tabular}{|c|c|c|c|c|c|}
\hline $\begin{array}{c}\text { Material's } \\
\text { Condition }\end{array}$ & $\begin{array}{c}\text { Temperature } \\
\left({ }^{\circ} \mathrm{C}\right)\end{array}$ & $\begin{array}{c}\text { Young's } \\
\text { Modulus } \\
(\mathbf{G P a})\end{array}$ & $\begin{array}{c}\text { Yield } \\
\text { Strength } \\
{[\mathbf{R p 0 . 2 \%}]} \\
(\mathbf{M P a})\end{array}$ & $\begin{array}{c}\text { Ultimate } \\
\text { Tensile } \\
\text { Strength } \\
(\mathbf{M P a})\end{array}$ & $\begin{array}{c}\text { Elongation } \\
(\%)\end{array}$ \\
\hline As-received & $\mathrm{RT}$ & $195 \pm 3$ & $551 \pm 2$ & 991 & 39 \\
\hline \multirow{2}{*}{$\begin{array}{c}\text { Solution } \\
\text { Treated }\end{array}$} & $\mathrm{RT}$ & $193 \pm 2$ & $528 \pm 3$ & 965 & 42 \\
\cline { 2 - 6 } & 620 & $184 \pm 8$ & $470 \pm 2$ & 778 & 48 \\
\cline { 2 - 6 } & 670 & $175 \pm 10$ & $549 \pm 1$ & 819 & 43 \\
\cline { 2 - 6 } & 720 & $167 \pm 3$ & $675 \pm 9$ & 787 & 44 \\
\hline
\end{tabular}

\subsection{Stress Relaxation}

Figure $8 \mathrm{a}$ and $\mathrm{b}$ respectively, show the stress-strain curves and their corresponding stress-time curves for the stress relaxation tests conducted on the solution treated microstructure at $720^{\circ} \mathrm{C}$ under different levels of applied strains $\left(\varepsilon_{\mathrm{op}}\right)$. Due to the different levels of plastic deformation, the applied stress at the start of stress relaxation tests (i.e. $\sigma_{0}$ ) has different magnitudes. It can clearly be seen that in the stress-time curve, the stress tends toward a non-zero asymptotic value of $\sigma_{\infty}$, as highlighted in Figure $8 \mathrm{~b}$ for the sample deformed to $2.1 \%$ strain. The relaxation curves recorded for the samples tested at $620^{\circ} \mathrm{C}, 670^{\circ} \mathrm{C}$ and $770^{\circ} \mathrm{C}$ are similar to those shown for $720^{\circ} \mathrm{C}$ in Figure 8. 

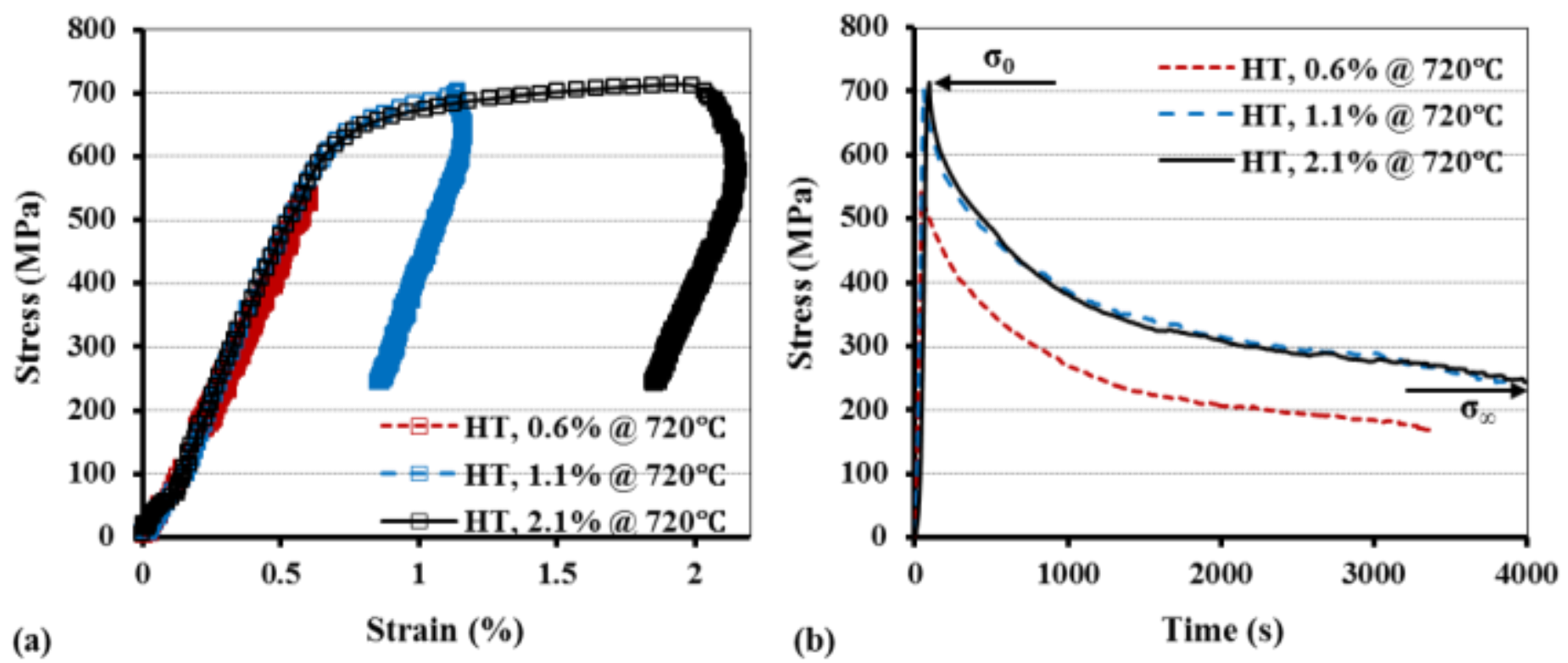

Figure 8: Stress relaxation tests at $720^{\circ} \mathrm{C}$ with different initial strains of $0.6 \%, 1.1 \%$ and $2.1 \%$ on the solution treated (i.e. 1 hour at $980^{\circ} \mathrm{C}$ ) material (a) stress-strain, and (b) stress-time.

The initial applied stress $\left(\sigma_{0}\right)$ and the non-zero asymptotic stress $\left(\sigma_{\infty}\right)$ for all of the stress relaxation tests are extracted from the recorded data based on the methodology described in the experimental procedure. The relationships between the non-zero asymptotic stress $\left(\sigma_{\infty}\right)$ and the initial relaxation stress $\left(\sigma_{0}\right)$ are shown in Figure 9 for the tests conducted at different temperatures. These plots show that at a given temperature the $\sigma_{\infty} / \sigma o$ ratio tends to remain in the same order, disregarding the magnitude of the initial applied stress $(\sigma 0)$ (i.e. different percentages of plastic deformation). This interesting parameter may be the material's characteristic behaviour. It can be seen that with an increase in the test temperature the $\sigma_{\infty} / \sigma_{0}$ ratio decreases rapidly, in particular when the temperature is increased beyond $720^{\circ} \mathrm{C}$. This is shown in Figure 10 for more clarity. 

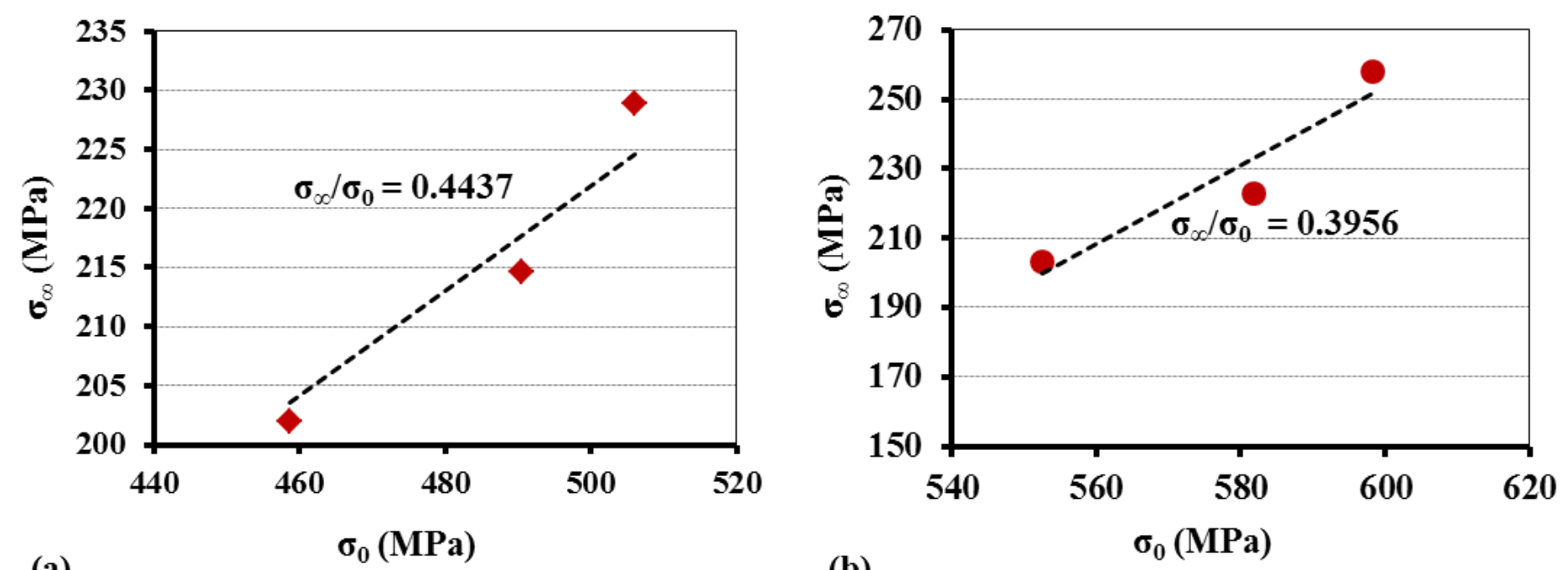

(a)

(b)
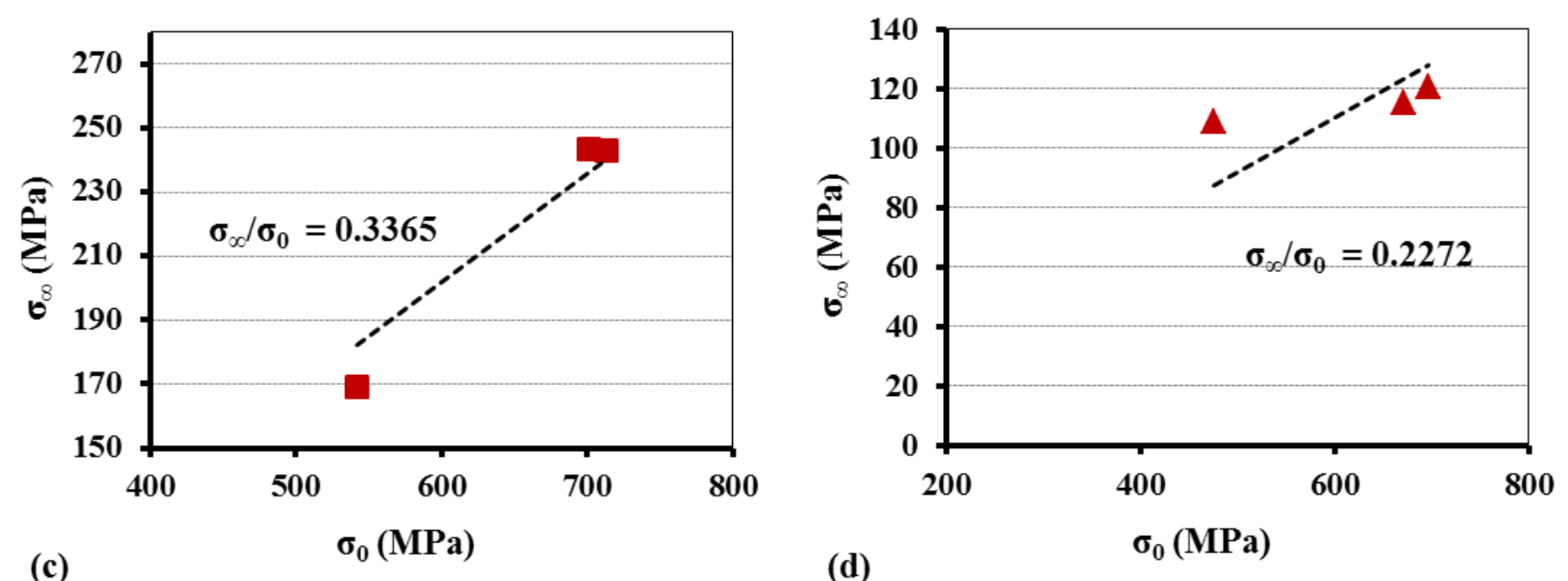

Figure 9: Variation of asymptotic stress $\left(\sigma_{\infty}\right)$ as a function of initial relaxation stress $\left(\sigma_{0}\right)$ at $(\mathrm{a}) 620^{\circ} \mathrm{C},(\mathrm{b}) 670^{\circ} \mathrm{C}$, (c) $720^{\circ} \mathrm{C}$ and (d) $770^{\circ} \mathrm{C}$. 


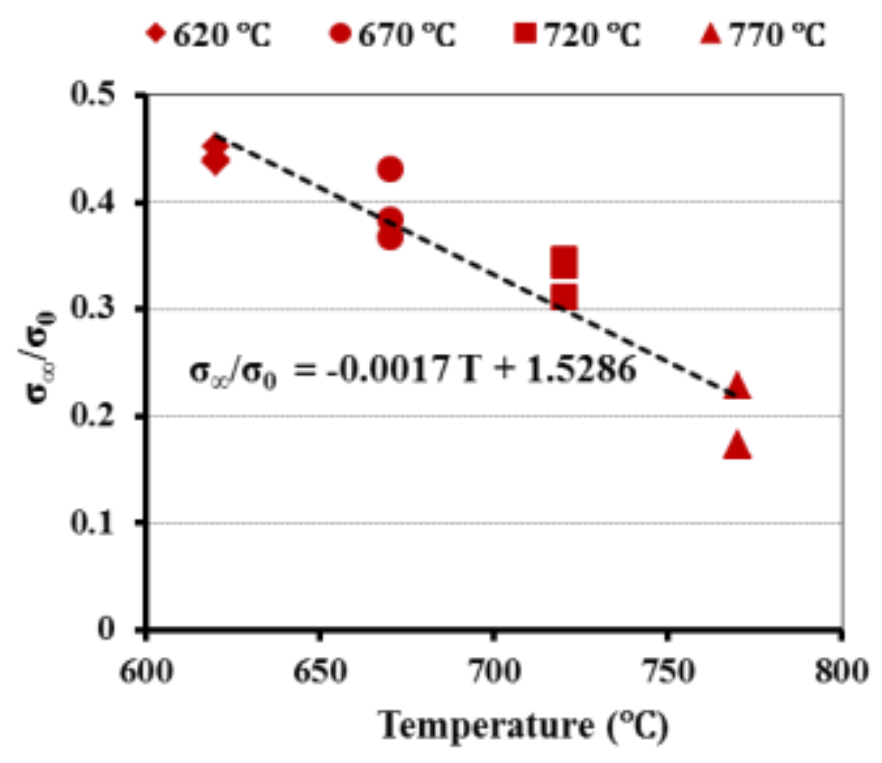

Figure 10: The variation of $\sigma_{\propto} / \sigma_{0}$ ratio with temperature for the stress relaxation experiments on heat treated IN718.

\section{Discussion}

\subsection{Microstructure}

One of the heat treatment routes practiced in industry to achieve IN718 parts with appropriate strength is solution annealing at a temperature range of $926^{\circ} \mathrm{C}-1010^{\circ} \mathrm{C}$ followed by rapid cooling (i.e. water quenching). For turbine disc applications, the final forging stage of IN718 usually takes place at $980^{\circ} \mathrm{C}$ which is just below the $\delta$-phase solvus temperature followed by water quenching. Choosing this temperature is imperative to control the grain size through grain boundary pinning by existing $\delta$-phase at the grain boundaries $[1,4]$. The water quenching process from the forging temperature is to control the size and distribution of $\gamma^{\prime \prime}$ during the subsequent age hardening heat treatments. The growth rate and volume fraction of the major age hardening phase (i.e. $\left.\gamma^{\prime \prime}\right)$, is strongly dependant on the cooling rate from the solution treatment temperature (i.e. $980^{\circ} \mathrm{C}$ ) such that faster cooling rates results in the faster nucleation and growth of $\gamma^{\prime \prime}$ [3]. The water quenching however leads to the generation of significant magnitudes of residual stress [12-16]. The forged material then undergoes precipitation hardening at $718^{\circ} \mathrm{C}$ for 8 hours, followed by furnace cooling to $621^{\circ} \mathrm{C}$, then held at this temperature for a total aging time of 18 hours, followed by air cooling. The purpose of this work was to evaluate the effect of heat treatment at the age hardening temperature range (i.e. $620^{\circ} \mathrm{C}-770^{\circ} \mathrm{C}$ ) on the relaxation of these residual stresses, aiming at constructing an empirical relationship that can be used for modelling and simulations purposes.

Figure 5 shows that one hour solution treatment at $980^{\circ} \mathrm{C}$ has resulted in dissolution of $\delta$-phase content from an initial $8 \pm 2 \%$ to $5 \pm 1 \%$ (i.e. by $\approx 3-4 \%$ ). This is consistent with previous observations where an empirical model has been proposed to predict the evolution of $\delta$-phase content as functions of temperature and time [7]. The time required to obtain chemical equilibrium at the grain scale was found to be very much dependant on temperature. It was shown that the $\delta$-phase content reduced tangentially to $\approx 0 \%$ at $1010^{\circ} \mathrm{C}$ after 6 minutes, and $\approx 2.5 \%$ at $985^{\circ} \mathrm{C}$ after 6 hours, from an initial content of $5.5 \pm 0.5 \%$ [7]. In the current study, although the exposure time at $980^{\circ} \mathrm{C}$ was only for one hour, a significant fraction of $\delta$ phase was dissolved $(\approx 3-4 \%)$ which can be due to the relatively high fraction of $\delta$-phase in the as received material $(\approx 10 \%)$. In addition to the $\delta$-phase dissolution, the morphology of the remnant $\delta$-phase is changed 
from predominantly plate-like shape in the as received material to mainly spheroids after solution treatment at $980^{\circ} \mathrm{C}$ (see Figure 5). This is because the morphology of $\delta$-phase is mainly dependant on the heat treatment temperature such that the stable morphology over $1010^{\circ} \mathrm{C}$ is spheroidal and below $930^{\circ} \mathrm{C}$ is plate-like. Previous studies have shown that solution treatments at $950^{\circ} \mathrm{C}$ and $985^{\circ} \mathrm{C}$, which are between these two extreme temperatures, resulted in a combination of both spheroidal and platelike morphologies that are both similar to the results observed in this study (see Figure 5) [7, 30].

No significant grain growth has been observed (i.e. only $\approx 1 \mu \mathrm{m}$ ) after solution treatment of the as received material at $980^{\circ} \mathrm{C}$ (see Figure 6). Previous observation has shown that no grain growth occurs at $985^{\circ} \mathrm{C}$ in microstructures containing over $4 \% \delta$-phase [31], however, later reports showed with $\approx 2.5 \% \delta$-phase, which is an equilibrium content at this temperature, although the grain growth kinetic was significantly slower, it had not completely stopped [7]. It has been reported that the plate-like $\delta$-phase is more efficient in preventing grain growth during solution treatment compared to spheroids morphology [7]. This is consistent with the results observed in this study as the grain growth had not entirely stopped (see Figure 6), and this can be due to the significant fraction of $\delta$-phase with spheroid morphology (Figure $5)$.

In addition to the small grain growth and $\delta$-phase spheroidisation, the solution heat treatment at $980^{\circ} \mathrm{C}$ has resulted in the rearrangement of grain boundaries and local lattice disorientation intragranularly. These are manifested in the form of a significant reduction in the fraction of low angle grain boundaries (LAGBs), from $\approx 18 \pm 2 \%$ in the as received to $7 \pm 3 \%$ in the solution treated condition, and an increase in the fraction of boundaries with $60^{\circ}$ misorientation (i.e. from $\approx 27 \%$ to $\approx 33 \%$ ), as shown in Figure 11a, b. The significant fraction of LAGBs and substructures in the misorientation angle distribution of the as received material (i.e. $2^{\circ}-7^{\circ}$ in Figure $11 \mathrm{a}$ ) can be the lattice distortions caused by second phase particles that is reduced drastically after solution treatment (Figure 11b). The peaks in the misorientation angle distribution plots in Figure 11 correspond to the $60^{\circ} /<111>\left(\sum 3\right)$ misorientation, as has clearly been shown in the misorientation axis distribution in Figure 12, that is a characteristic of coherent twin boundaries [32]. The increase in the fraction of $\sum 3$ twin boundaries after heat treatments (see Figure 11) is not due to twinning mechanism taking place during heat treatments as similar to those observed in thermo-mechanically processed materials $[33,34]$, but rather is due to the rearrangement of the boundaries that are slightly misaligned (i.e. by $\approx 5^{\circ}$ ) from the $60^{\circ}$ misorientation angle. Further aging heat treatments at $720^{\circ} \mathrm{C}$ and $770^{\circ} \mathrm{C}$ have led to the fine tuning of grain boundaries [32] in a form of complete elimination of LAGBs and the boundaries with misorientations slightly deviated from $60^{\circ}$ angle (see Figure $11 \mathrm{c}, \mathrm{d}$ ). 


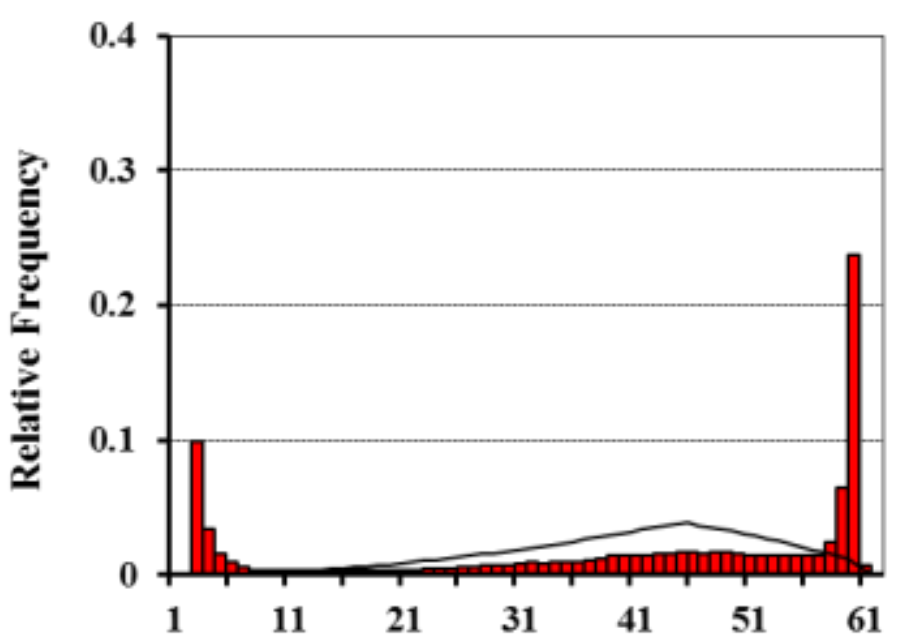

(a)

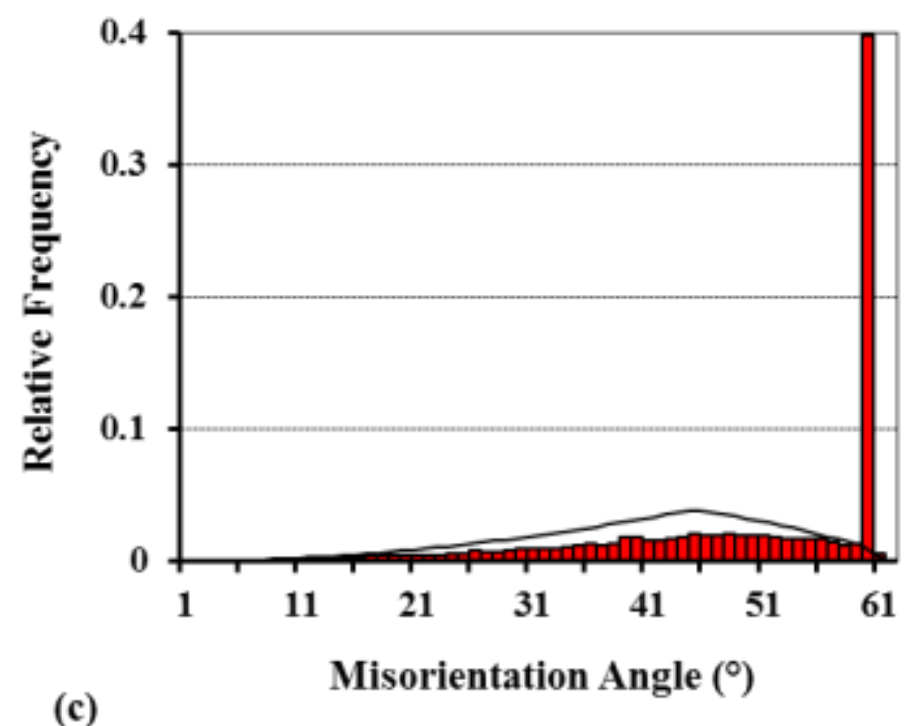

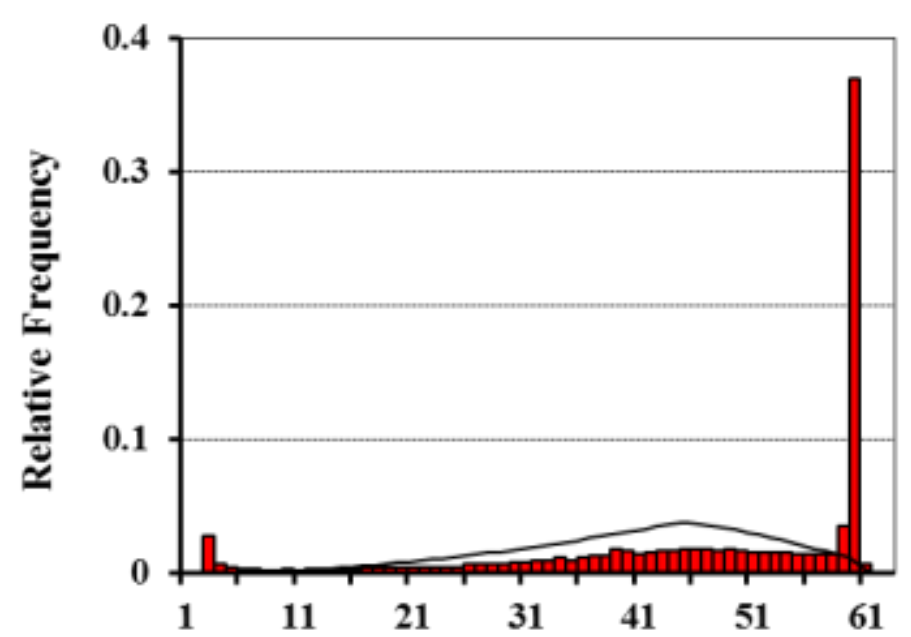

(b) Misorientation Angle $\left({ }^{\circ}\right)$

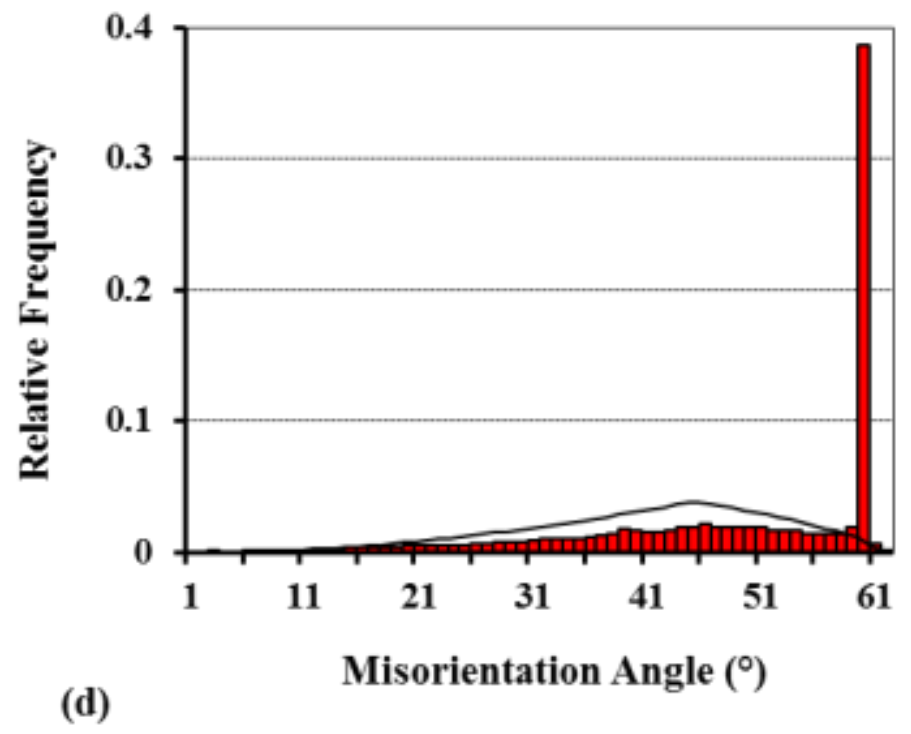

(d)

Figure 11: Plots of misorientation angle distribution for the IN718 material used in this study in (a) as received condition, (b) after 1 hour solution treatment at $980^{\circ} \mathrm{C}$, (c) after stress relaxation experiment at $720^{\circ} \mathrm{C}$, and (d) after stress relaxation experiment at $770^{\circ} \mathrm{C}$. 

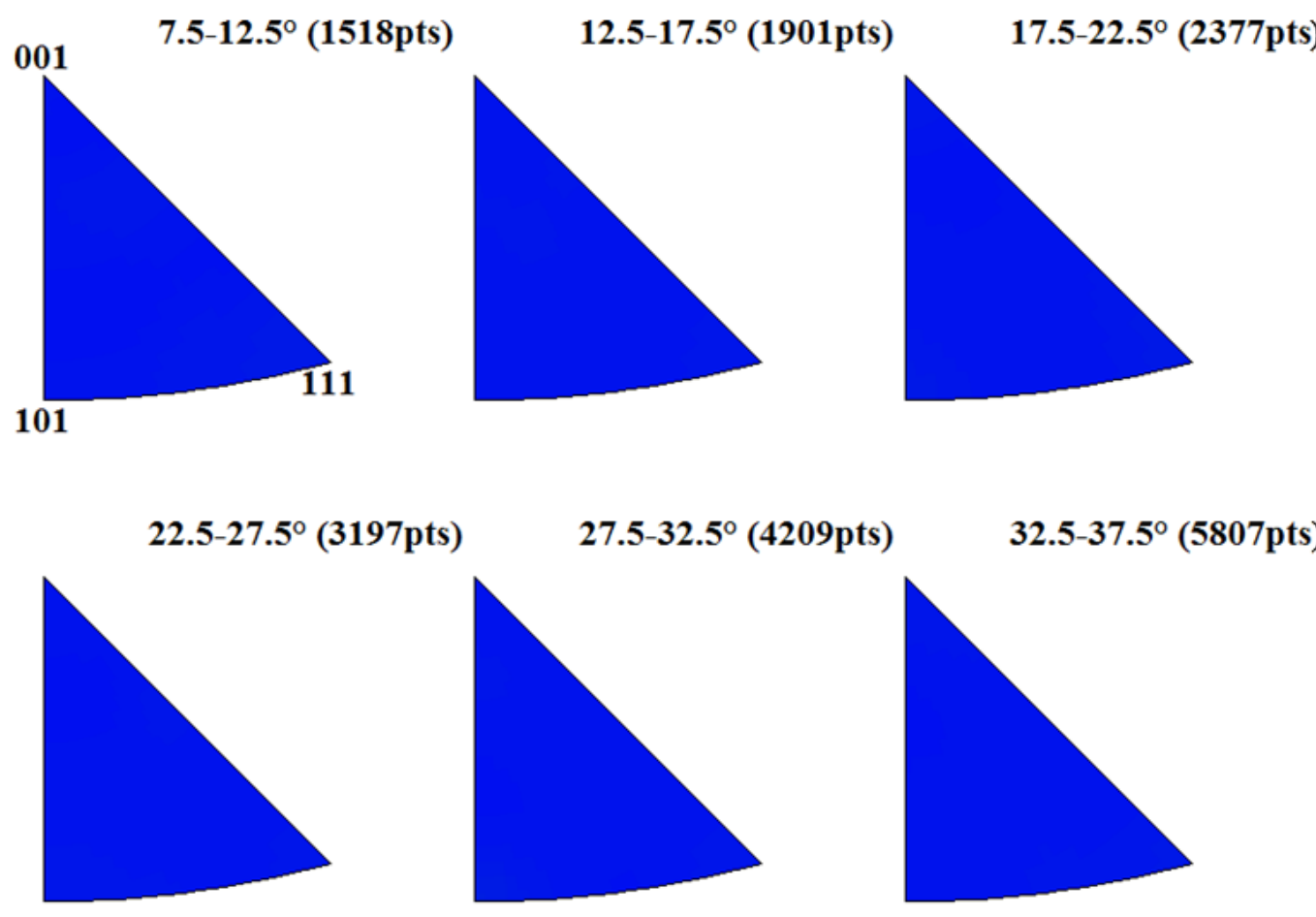

32.5-37.5 ${ }^{\circ}$ (5807pts)

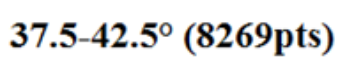

$42.5-47.5^{\circ}(8865 \mathrm{pts})$

$47.5-52.5^{\circ}(8311 \mathrm{pts})$
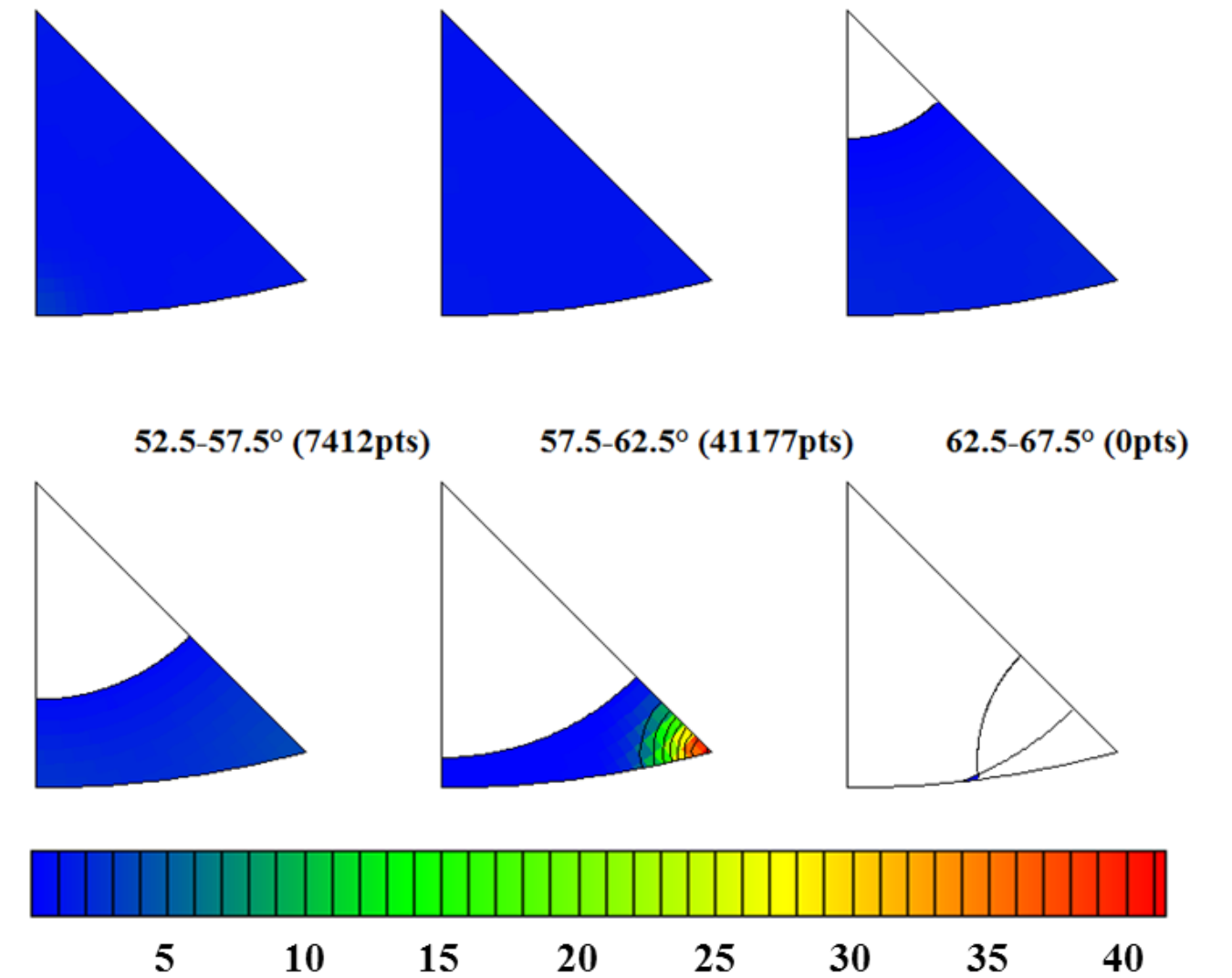

Figure 12: Misorientation axis distribution plot for the IN718 material used in this study, after solution treatment at $980^{\circ} \mathrm{C}$ for 1 hour, in $5^{\circ}$ angle sections, emphasising a drastically high intensity peak at $60^{\circ}<111>$. The plot of misorientation angle distribution for the same data is shown in Figure 11(b). 


\subsection{Stress Relaxation}

Components made from IN718 are exposed to the highest thermal and complex mechanical loadings. One of the important consequences of these extreme conditions is the deformation and dimensional changes induced by stress relaxation and/or creep mechanisms [20]. The relaxation curves (i.e. stress as a function of time) shown in Figure 8 can be represented by either a logarithmic law (Equation 6) or a hyperbolic law (Equation 7) [35].

$$
\begin{gathered}
\sigma(t)=\sigma_{0}-a \cdot \ln (b t+1) \\
\sigma(t)=\sigma_{\infty}+b(t+a)^{-m}
\end{gathered}
$$

Equation 6

Equation 7

For all of the stress relaxation tests conducted during the course of this study (e.g. Figure 8b), the hyperbolic law was found to be the most appropriate way of describing the curves. This was firstly due to the long time tendency of the stress towards an asymptotic non-zero value (see Figure 9 and Figure 10), and secondly plotting the derivative $d \sigma(t) / d t$ against time in the logarithmic scale results in a linear plot with a slope equal to $-(m+1)$ which is different from $(-1)$ of the Logarithmic law expressed in Equation 6. Transforming by natural logarithm, the hyperbolic law expressed in Equation 7 obtains a new form presented in Equation 8.

$$
\ln \left[\sigma(t)-\sigma_{\infty}\right]=\ln b-\operatorname{mln}(t+a)
$$

Equation 8

Replacing the measured asymptotic stress $\left(\sigma_{\infty}\right)$ for each experiment in Equation 8 and by plotting the $\ln [\sigma(t)$ - $\left.\sigma_{\infty}\right]$ term as a function of $(t+a)$, a decreasing straight line is obtained in logarithmic coordinates from which " $m$ " and " $b$ " can be determined (see Figure 13). In fact " $m$ " is the slope of the fitted straight line and " $b$ " is a value at which the fitted line intersects the horizontal axis (i.e. $\ln \left[\sigma(t)-\sigma_{\infty}\right]$ ). This is shown in Figure 13 for the stress relaxation test carried out at $720^{\circ} \mathrm{C}$ with an initial strain of $2.1 \%$. To determine the only unknown parameter (i.e. a), the "curve fitting"' toolbox in MATLAB (version R2013a) has been used to identify the best " $a$ " parameter by having a best fit to the experimental data with $95 \%$ confidence. As an example, this procedure is shown in Figure 14 for the stress relaxation data obtained for the test conducted at $720^{\circ} \mathrm{C}$ with an initial strain of $2.1 \%$. A fitted curve to the experimental data (red line in Figure 14), by using the determined " $a$ ", " $b$ " and " $m$ " parameters, shows a reliable (95\% confidence) fit with the measured data. The assessed parameters along with the experimental data for all of the stress relaxation tests performed in this study are summarised in Table 4. Detailed examination of the numerical values obtained for coefficients " $a$ " and " $b$ " revealed that they are extremely sensitive to the exact values of " $m$ " because of the mathematical form of the hyperbolic law. 


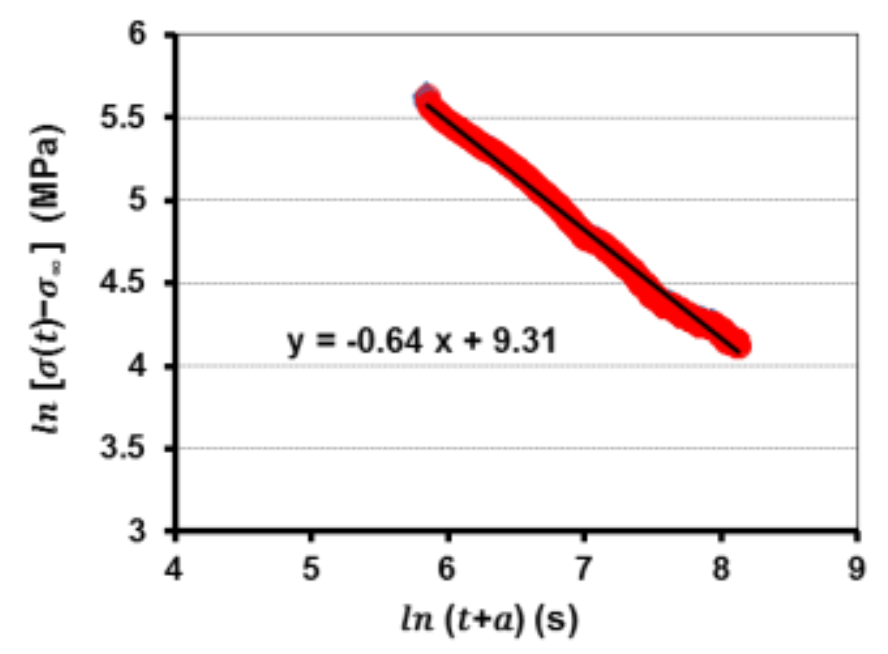

Figure 13: Example of fitted curve for the determination of " $b$ " and " $m$ " parameters of the stress relaxation experiments conducted at $720^{\circ} \mathrm{C}$ with an initial strain of $2.1 \%$. The stress relaxation data for this particular test is shown in Figure 8.

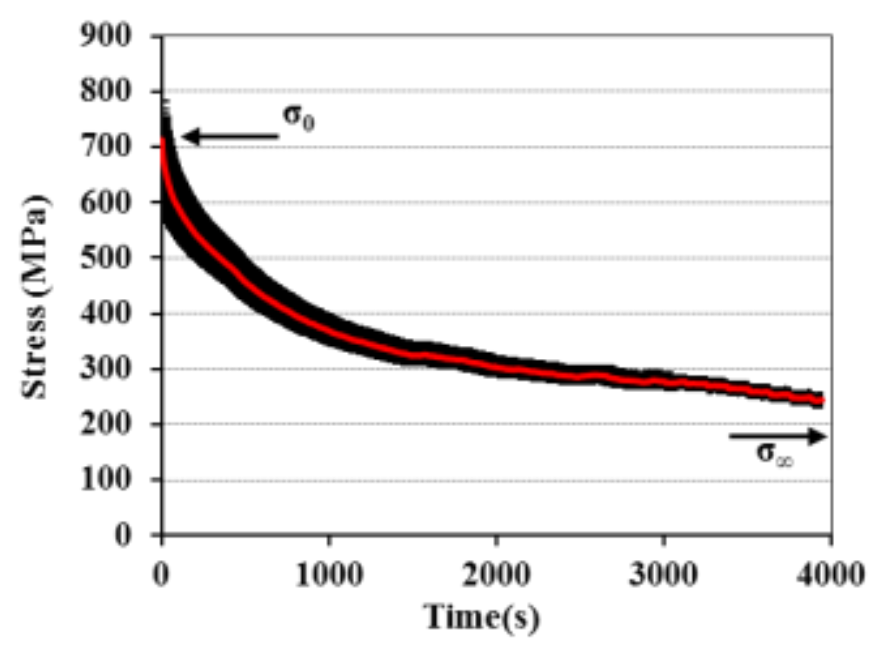

Figure 14: A fitted curve with $95 \%$ confidence bound to the experimental stress relaxation data conducted at $720^{\circ} \mathrm{C}$ with an initial strain of $2.1 \%$, to determine the " $a$ " parameter.

Table 4: Experimental data and numerically adjusted values of the parameters of the hyperbolic law (i.e. $\left.\sigma(t)=\sigma_{\infty}+b(t+a)^{-m}\right)$ for the stress relaxation experiments carried out in this study.

\begin{tabular}{|c|c|c|c|c|c|c|}
\hline \multirow{2}{*}{$\begin{array}{c}\text { Temperature } \\
\left({ }^{\circ} \mathrm{C}\right)\end{array}$} & \multirow{2}{*}{$\begin{array}{c}\text { Initial } \\
\text { Strain } \\
(\%)\end{array}$} & \multirow{2}{*}{$\begin{array}{c}\text { Initial } \\
\text { Stress }\left(\sigma_{0}\right) \\
\left(1^{6} \mathbf{P a}\right)\end{array}$} & \multirow{2}{*}{$\begin{array}{c}\text { Asymptotic } \\
\text { Stress }\left(\sigma_{\infty}\right) \\
\left(10^{6} \mathrm{~Pa}\right)\end{array}$} & \multicolumn{3}{|c|}{ Numerically Adjusted Parameters } \\
\hline & & & & m & $\mathbf{a}(\mathbf{s})$ & $\begin{array}{c}\text { b } \\
\left(10^{9} \text { S.I. unit }\right)\end{array}$ \\
\hline 620 & $\begin{array}{l}0.5 \\
1.1 \\
2.1\end{array}$ & $\begin{array}{l}459 \\
491 \\
506\end{array}$ & $\begin{array}{l}202 \\
215 \\
229\end{array}$ & $\begin{array}{l}0.79 \pm 0.2 \\
0.71 \pm 0.3 \\
0.72 \pm 0.2\end{array}$ & $\begin{array}{l}440 \pm 26 \\
135 \pm 23 \\
347 \pm 24\end{array}$ & $\begin{array}{l}2.34 \\
2.15 \\
1.95\end{array}$ \\
\hline 670 & $\begin{array}{l}0.5 \\
1.1 \\
2.1\end{array}$ & $\begin{array}{l}553 \\
582 \\
598\end{array}$ & $\begin{array}{l}203 \\
223 \\
258\end{array}$ & $\begin{array}{l}0.64 \pm 0.1 \\
0.65 \pm 0.1 \\
0.66 \pm 0.1\end{array}$ & $\begin{array}{c}200 \pm 10 \\
121 \pm 5 \\
210 \pm 3\end{array}$ & $\begin{array}{l}1.27 \\
1.02 \\
1.43\end{array}$ \\
\hline
\end{tabular}




\begin{tabular}{|c|c|c|c|c|c|c|}
\hline 720 & 0.5 & 542 & 169 & $0.63 \pm 0.1$ & $80 \pm 5$ & 0.74 \\
& 1.1 & 702 & 244 & $0.64 \pm 0.1$ & $121 \pm 4$ & 1.11 \\
& 2.1 & 714 & 243 & $0.64 \pm 0.1$ & $115 \pm 3$ & 1.10 \\
\hline \multirow{3}{*}{770} & 0.5 & 476 & 109 & $0.62 \pm 0.2$ & $160 \pm 15$ & 1.28 \\
& 1.1 & 672 & 115 & $0.59 \pm 0.2$ & $200 \pm 12$ & 1.2 \\
& 2.1 & 696 & 120 & $0.6 \pm 0.1$ & $178 \pm 10$ & 0.90 \\
\hline
\end{tabular}

Experimental difficulties are often encountered with the determination of the asymptotic stress $\left(\sigma_{\infty}\right)$ in terms of detecting an appropriate value for $\sigma_{\infty}$. In order to obtain correct values for $\sigma_{\infty}$ throughout this investigation, incremental unloading was carried out until a detectable negative relaxation rate was achieved which is an indication of the lower bound for $\sigma_{\infty}$. Also, an alternative way of checking the authenticity of $\sigma_{\infty}$ was to make sure that the experimental estimations of $\sigma_{\infty}$ were compatible with the hyperbolic description of the relaxation law for the smaller values of time. Similar type of difficulties has been observed when measuring the friction stresses associated with zero creep rates [36]. The most robust method of the determination of $\sigma_{\infty}$ is to measure the creep threshold of the same material with the same sample geometry [37], however, the incremental unloading approach was considered to be accurate enough for this study.

\section{Conclusion}

In this study, the stress relaxation behaviour in a quenched solution treated IN718 nickel based superalloy during aging has been investigated. The major observations of this work are concluded as follows:

- The tensile stress relaxation experiments proved the presence of a non-zero asymptotic relaxation stress $\left(\sigma_{\infty}\right)$ that is proportional to the applied initial stress $\left(\sigma_{0}\right)$ in the beginning of the test. This is an indication of the activation of stress sensitive microstructure mechanisms such as cutting or a climbby-pass process of dislocations around $\gamma^{\prime}, \gamma^{\prime \prime}$ precipitates.

- The non-zero asymptotic stress $\left(\sigma_{\infty}\right)$ appears to be proportional to the initially applied stress $\left(\sigma_{0}\right)$ for a fixed temperature. It has been shown that the $\sigma_{\infty} / \sigma_{0}$ ratio decreases rapidly with increasing temperature at the aging temperature range (i.e. $620^{\circ} \mathrm{C}-720^{\circ} \mathrm{C}$ ) investigated in this study.

- The relaxation curves are described by a hyperbolic law and the parameters of this law have been determined through numerical analysis and curve fitting. This hyperbolic law can then be implemented in simulation models for predicting stress (applied/residual) relaxation during aging heat treatment.

- A small grain growth has been observed during solution treatment of the as received IN718 which can be due to a significant reduction in the fraction of $\delta$-phase and spheroidisation of the remaining $\delta$-phase that are less efficient in the pinning of the grain boundaries.

\section{Acknowledgements}

The authors would like to acknowledge the support provided by Aubert \& Duval, TIMET, Boeing, Rolls Royce and Barnes Aerospace. The experimental works were carried out at the Advanced Forming Research Centre (AFRC), University of Strathclyde, which receives partial financial support from the UK's High Value Manufacturing CATAPULT. 


\section{References}

[1] A. Niang, B. Viguier, J. Lacaze, Mater. Charact., 61 (2010) 525 - 534.

[2] M. E. Mehl, J. C. Lippold, in: E.A. Loria (Ed.) Superalloys 718,625,706 and Various Derivatives, The Minerals, Metals \& Materials Society, Pittsburgh, Pennsylvania, 1997, pp. 731 - 741.

[3] J. W. Brooks, P. J. Bridges, in: S. Reichman, D.N. Duhl, G. Maurer, S. Antolovich and C. Lund (Ed.) Superalloys 1988, The Metallurgical Society, 1988.

[4] M. Dehmas, J. Lacaze, N. Niang, B. Viguier, Adv. Mater. Sci. Eng., 2011 (2011) 1 - 9.

[5] S. Azadian, L. Y. Wei, F. Niklasson, R. Warren, in: E.A. Loria (Ed.) Superalloys 718, 625 and various derivatives, Minerals, Metals \& Materials Society, Warrendale, PA7, 2001.

[6] C-M. Kuo, Y-T. Yang, H-Y. Bor, C-N. Wei, C-C. Tai, Mat. Sci. and Eng. A, 510 - 511 (2009) 289 294.

[7] Y. Desvalle'es, M. Bouzidi, F. Bois, N. Beaude, in: E.A. Loria (Ed.) Superalloy 718-metallurgy and applications, Minerals, Metals \& Materials Society, Warrendale, PA7 1994, pp. 281 - 291.

[8] G. Sjfberg, N. G. Ingesten, in: E.A. Loria (Ed.) Superalloy 718-metallurgy and applications, Minerals, Metals \& Materials Society, Warrendale, PA7, 1991, pp. $603-621$.

[9] J. F. Muller, M. J. Donachie, Superalloys a technical guide, ASM international, Materials Park, OH7, 1975.

[10] C. Slama, M. Abdellaouib, J. Alloys Compd., 306 (2000) 277-284.

[11] M. Preuss, P. J. Withers, G. J. Baxter, Mat. Sci. and Eng. A, 437 (2006) 38-45.

[12] S. Denis, S. Sjöström, A. Simon, Metall. Trans. A, 18 (1987) 1203 - 1212.

[13] B. Smoljan, J. Mater. Eng. Perf, 11 (2002) 75 - 79.

[14] M.T. Todinov, Modell. Simul. Mater. Sci. Eng., 7 (1999) 25-41.

[15] Y. Nagasaka, J. K. Brimacombe, E. B. Hawbolt, I. V. Samarasekera, B. Hernandez-Morales, S. E. Chidiac, Metall. Trans. A, 24 (1993) 795-808.

[16] Y. V. L. N. Murthy, G. Venkata Rao, P. Krishna Iyer, Comput. Struct., 60 (1996) 131 - 154.

[17] G. A. Webster, A.N. Ezeilo: , 2001, vol. 23, pp. , Int. J. Fatgiue, 23 (2001) 375 - 383.

[18] G.A. Webster, Mater. Sci. Forum, 347 - 349 (2000) 1 - 11.

[19] ASTM, Standard Test Methods for Stress Relaxation for Materials and Structures, E 328 - 022008.

[20] U. Martin, U. Mühle and H. Oettel, Mech. Time-Depend. Mater. , 2 (1998) 1 - 12.

[21] ASTM, Standard Test Methods for Tension Testing of Metallic Materials, Designation: E 8 - 04. 
[22] A. S. Krausz, H. Eyring, Deformation Kinetics, Wiley-Interscience, New York, 1975.

[23] C. N. Ahlquist, W. D. Nix, Scripta Met., 3 (1969) 679 - 681.

[24] G. B. Gibbs, Phil. Mag., 13 (1966) 317 - 329.

[25] G. Sargent, H. Conrad, Scripta Met. , 3 (1969) 43 - 49.

[26] F. Guiu, Scripta Met. , 3 (1969) 753-755.

[27] K. Okazaki, Y. Aono, T. Kaneyuki, Mater. Sci. Eng., 33 (19778) 253-266.

[28] R. E. Reed-Hill, J. R. Donoso, Scripta Mater., 9 (1975) 1305 - 1308.

[29] S. R. MacEwen, O. A. Kupcis, B. Ramaswami, Scripta Met., 3 (1969) 441-448.

[30] M. Sundararaman, P. Mukhopadhyay, S. Banerjee, Metall. Trans. A, 19 (1988) 453-465.

[31] A. W. Dix, J. M. Hyzak, R. P. Singh, in: S. D. Antolovich, R. W. Stusmd, R. A. MacKay, D. L. Anton, T. Khan, R. D. Kissinger, D. L. Klarstmm (Ed.), The Minerals, Metals \& Materials Society, 1992.

[32] C. B. Thomson, V. Randle, Acta Mater., 45 (1997) 4909-4916.

[33] S. Rahimi, D. L. Engelberg, T. J. Marrow, Corros. Sci., 53 4213-4222.

[34] S. Rahimi, D. L. Engelberg, J. A. Duff, T. J. Marrow, J. Microsc., 233 (2009) 423-431.

[35] G. Baur, P. Lehr, M\&m. Sci Rev. Metall., Mém. Sci. Rev. de Métallurgie, 551 (1975) 7 - 8.

[36] M. McLean, Acta Mater., 33 (1985) 545-556.

[37] P. Caron, P. J. Henderson, T. Khan, M. McLean, Scripta Mater., 20 (1986) 875 - 880. 